九州大学学術情報リポジトリ

Kyushu University Institutional Repository

\title{
Micromechanical modeling for the in-plane mechanical behavior of orthogonal 3D woven ceramic matrix composites with transverse and matrix cracking
}

Onodera, Sota

Department of Aerospace Engineering, Tohoku University

Tsuyuki, Junpei

Department of Aerospace Engineering, Tohoku University

Okabe, Tomonaga

Department of Aerospace Engineering, Tohoku University

ht tp://hdl. hand le. net/2324/4482059

出版情報: International Journal of Damage Mechanics, 2021-06-24. SAGE Publications バージョン:

権利関係: Reprints and permission: sagepub.co.uk/journalsPermissions. nav 


\title{
Micromechanical modeling for the in-plane mechanical behavior of orthogonal 3D woven ceramic matrix composites with transverse and matrix cracking
}

Sota Onodera ${ }^{1}$, Junpei Tsuyuki ${ }^{1}$ and Tomonaga Okabe ${ }^{1,2}$

\begin{abstract}
Ceramic matrix composites (CMCs) are currently being considered for applications in the hot-section components of aviation gas turbines owing to their favorable characteristics. Herein, a micromechanical modeling is presented for orthogonal 3Dwoven CMCs under in-plane loading. The three-dimensional effective compliance of the 3D woven composite was derived using three-dimensional laminate theory and continuum damage mechanics. The damage variables were used to describe the stiffness reduction due to the transverse and matrix cracking in each fiber bundle. The calculation method for the transverse and matrix cracking evolutions under in-plane loading was established by introducing mixed-mode damage criteria. The stress redistribution among the fiber bundles of 3D woven CMCs due to the fiber/matrix interfacial debonding around matrix cracking was considered to capture the interaction between the matrix and transverse crack evolutions. Additionally, a mesomechanical model comprising finite element analysis and damage mechanics was established to evaluate the stress perturbation due to the geometry of the woven structure. The edge face of the $3 \mathrm{D}$ woven $\mathrm{CMC}$ was experimentally observed to measure the transverse and matrix cracks that occurred in each fiber bundle. The transverse and matrix crack densities predicted by the micromechanical and mesomechanical models reasonably agreed with the experimental results up to crack saturation. Furthermore, the micromechanical model reproduced the nonlinear stress-strain response under tensile and shear loading using mixed-mode damage criteria.
\end{abstract}




\section{Keywords}

Ceramic matrix composites (CMCs), microcracking, micromechanical modeling, multiscale, continuum damage mechanics

\section{Introduction}

Ceramic matrix composites (CMCs) have promising applications in the hot components of aircraft gas turbine engines (Zok, 2016). They have lower density and higher temperature capabilities than current superalloys, which enables enhanced operating temperatures, thermal efficiency, and propulsive efficiencies of aircraft gas turbine engines (Ohnabe et al., 1999; Walock et al., 2018). They can be designed with the required mechanical properties by aligning the unidirectional plies or fiber bundles. In particular, CMCs with 3D woven fiber bundles exhibit high delamination resistance and tensile strengths, owing to their favorable through-thickness reinforcement (Cox et al., 1996; Ogi et al., 2010; Baucom and Zikry, 2005). However, orthogonal 3D woven CMCs exhibit nonlinear behavior at low stress levels because of their brittleness.

Typical damage observed in a 3D woven CMC subjected to monotonic tensile loading is shown in Fig. 1. Transverse cracks, which run parallel to the fibers, are first initiated in the fiber bundles perpendicular to the loading. When additional load is applied, matrix cracks, which run perpendicular to the fibers, form in the fiber bundle oriented parallel to the loading. At the matrix crack plane, fiber/matrix interfacial debonding occurs without fiber breakage; hence, the fibers bridge a matrix crack and crack opening is restricted (Sutcu and Hillig, 1990; Budiansky et al., 1986). The fibers in the
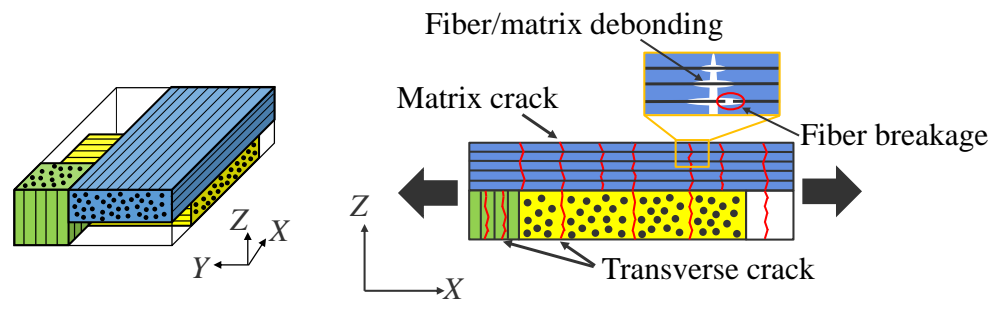

Figure 1. Multiple damage modes observed in a 3D woven CMC.

\footnotetext{
${ }^{1}$ Department of Aerospace Engineering, Tohoku University, 6-6-01, Aramaki Aza Aoba, Aoba-ku, Sendai, Miyagi, 980-8579, Japan

${ }^{2}$ Department of Material Science and Engineering, University of Washington, BOX 352120, Seattle, WA, 98195-2120, USA
}

\section{Corresponding author:}

Sota Onodera, Department of Aerospace Engineering, Tohoku University, 6-6-01, Aramaki Aza Aoba, Aoba-ku, Sendai, Miyagi, 980-8579, Japan

Email: sota.onodera.s8@dc.tohoku.ac.jp 
loading direction break near the matrix crack planes, and the composite eventually fails. These multiple damage modes at the microscale are the main factors responsible for nonlinearity.

Models for transverse cracking have been developed in the fields of polymer matrix composite laminates to evaluate the thermomechanical properties and transverse progression in cracked laminates. Numerous models, such as the shear-lag, (Berthelot, 2003; Lee and Daniel, 1990) variational, (Hashin, 1986; Hajikazemi et al., 2020; Vinogradov and Hashin, 2010) and continuum damage mechanics (CDM) (Talreja, 1985; Allen et al., 1987a,b; Murakami, 2012) models exist. In particular, CDM models demonstrate good compatibility with classical laminate theory; thus, they can readily analyze laminates with any stacking sequence. In the CDM approach, a damaged ply is homogenized and the damage progression is described by the damage variable. Therefore, it is essential to formulate the damage variable as a function of the parameters for which physical meaning is trivial. Okabe et al. (Okabe et al., 2018) and Onodera and Okabe (Onodera and Okabe, 2020) derived the damage variable associated with transverse cracking as a function of transverse crack density based on the micromechanical model. This proposed damage variable can be converted into transverse crack density, which is observed at the edge of the laminate, and transverse crack progression can be predicted based on strength and energy criteria.

Micromechanical models for unidirectionally reinforced brittle-matrix composites with matrix cracks have been extensively developed. Aveston et al. (Aveston et al., 1971) derived the minimum matrix cracking stress, known as the "ACK stress," by considering the zero fiber/matrix interfacial debonding energy and the constant interfacial shear stress. The maximum matrix cracking stress occurs when the slip between the fibers and the matrix is not considered (Budiansky et al., 1986). Hutchinson and Jensen (Hutchinson and Jensen, 1990) derived the debonding stress, which is a simple jump discontinuity of the axial stress, to account for the finite fiber/matrix interfacial debonding energy. Sutcu and Hilling (Sutcu and Hillig, 1990) investigated the effect of the finite interfacial debonding energy on the matrix cracking stress using a shearlag model. Mechanics models of statistical matrix crack evolution from initial cracking to the fully saturated state have been proposed based on the steady-state energy criterion (Zok and Spearing, 1992) or critical strain criterion (Curtin, 1993). Matrix crack evolution that considers the influence of matrix-rich regions on the initial crack growth was predicted by Okabe et al., (Okabe et al., 1999) while Curtin et al. (Curtin et al., 1998) formulated the tensile strength of a unidirectional brittle-matrix composite as a function of the fiber breaks and matrix cracks from single cracking to saturated cracking; they also predicted nonlinear stress-strain behavior up to failure. Hansen and Waas (Hansen and Waas, 2016) presented a micromechanical model to predict the stressstrain behavior of a unidirectional matrix composite comprising a matrix and fibers with a finite thick coating. Almost all the above-mentioned mechanical models assume the uniaxial loading condition, with limited analytical models that address CMCs under shear loading. Recently, Rajan and Zok (Rajan and Zok, 2014) formulated the minimum matrix cracking stress in unidirectional CMCs subjected to shear loading using the energy 
criterion (Budiansky et al., 1986). A micromechanical model capable of handling general loading must be developed to analyze the mechanical behavior of structural components.

Formulating the complete stress-strain behavior of a cross-ply laminate and woven CMCs is more complicated because of the interaction between the matrix and transverse cracks. Several researchers have studied the damage progression in crossply (Xia et al., 1993; Okabe et al., 1998; Kuo and Chou, 1995; Takeda and Kiriyama, 1999; Karandikar and Chou, 1993; Longbiao, 2015) CMCs under uniaxial loading. Kuo and Chou (Kuo and Chou, 1995) defined five damage modes depending on the combination of cracks that penetrate both $0^{\circ}$ and $90^{\circ}$ plies, cracks that only exist in $0^{\circ}$ plies, and fiber/matrix interfacial debonding around a matrix crack. They formulated the shear-lag model for each mode using the energy balance approach. Takeda and Kiriyama, (Takeda and Kiriyama, 1999) as well as Longbiao (Longbiao, 2015) established matrix and transverse crack evolutions using the previously mentioned approach adopted by Kuo and Chou. However, simultaneously managing all of the damage modes using the models developed by Kuo and Chou is difficult because of the inherent complexity. A one-dimensional analytical model that predicts the nonlinear stress-strain behavior of 3D woven CMCs was established by Ogasawara et al., (Ogasawara et al., 2004) which predicted the effective axial Young's modulus in a damaged 3D woven CMC. However, other elastic moduli, such as the effective shear modulus and effective Poisson's ratio, were not formulated. Three-dimensional effective compliance is required to evaluate the stress field of the components under complex loading using numerical analysis. In particular, the micromechanical model for cross-ply and 3D woven CMCs under shear loading has not been sufficiently developed.

Herein, a 3D micromechanical model was developed to predict the stress-strain behavior of 3D woven CMCs subjected to in-plane loading, including shear loading. The compliance of the 3D woven composite was calculated using three-dimensional laminate theory (Gudmundson and Zang, 1993). The CDM approach was used to describe the stiffness reduction of a unidirectional composite due to transverse and matrix cracking. The damage variables for transverse and matrix cracking were explicitly described using our established model (Onodera and Okabe, 2020) and the model developed by Curtin, (Curtin et al., 1998) respectively. The transverse and matrix crack progressions were analyzed by considering the effect of stress transfer due to fiber/matrix interfacial debonding. A mesomechanical model that uses finite element analysis (FEA) was established to validate the micromechanical model. The stress-strain behavior was investigated and an in situ crack for an orthogonal 3D woven Tyranno ${ }^{\mathrm{TM}} \mathrm{ZMI}$ fiber/SiTi-C-O matrix composite under in-plane loading observed and compared with the micromechanical and mesomechanical model predictions.

\section{Modeling}

\section{Micromechanical model}

A CDM-based analytical model for the nonlinear mechanical behavior of 3D woven $\mathrm{CMCs}$ resulting from multiple types of damage was developed. Here, two types of 3D 

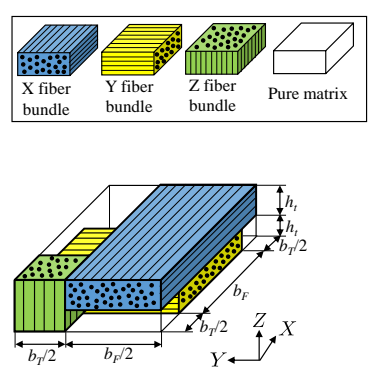

(a)
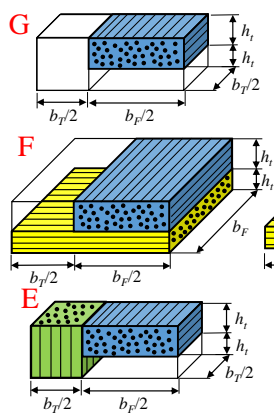

(b)

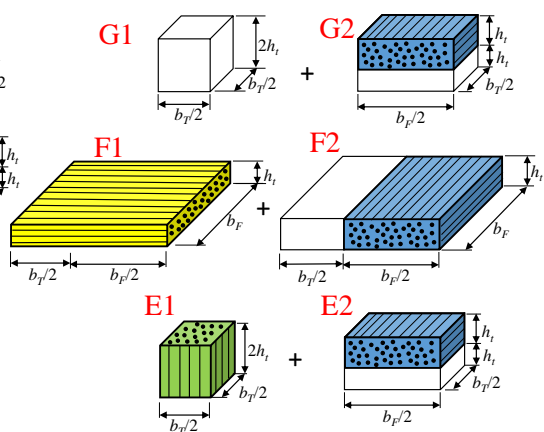

(c)

Figure 2. Schematic representation of (a) unit cell $A$, (b) components of unit cell $A$, and (c) subcomponents of regions $\mathrm{E}, \mathrm{F}$, and $\mathrm{G}$.

woven $\mathrm{CMC}$ material are considered. Figure 2 (a) depicts unit cell $\mathrm{A}$ in the orthogonal 3D woven Si-Ti-C-O/Si-Ti-C-O composite studied by Ogasawara et al., (Ogasawara et al., 2004) and Fig. 3 (a) shows unit cell B in the orthogonal 3D woven Tyranno ${ }^{\mathrm{TM}} \mathrm{ZMI} / \mathrm{Si}$ Ti-C-O composite investigated in this study. The coordinate system $(X, Y, Z)$ denotes the unit cell coordinate system. Unit cells A and B are constructed by the pure matrix region and three fiber bundles in the $X-, Y$-, and $Z$-directions. The $X$ - and $Y$-direction fiber bundles of unit cell A have the same width $b_{F}$ and thickness $h_{t}$, whereas the width and thickness of the $Z$-direction fiber bundle are represented by $b_{T}$. The widths of the fiber bundles of unit cell $\mathrm{B}$ in each direction is denoted by $b_{T j}(j=X, Y, Z)$, and the thicknesses of the $X$ - and $Y$-direction fiber bundles are denoted by $h_{t X}$ and $h_{t Y}$, respectively. The $Z$-direction fiber bundle thickness of unit cell $\mathrm{B}$ is $b_{T Z}$. The distance between $Z$ - and the other-directed fiber bundles of unit cell $\mathrm{B}$ is $h^{*}$.

In the micromechanical model, the macroscopic mechanical properties of 3D woven CMCs are obtained by homogenizing unit cells $\mathrm{A}$ and $\mathrm{B}$, which are one possible approximation of the repeating unit cell representing macroscopic mechanical properties (Ishikawa et al., 1998), because symmetric conditions are assigned on the $Y-Z$ and $Z-X$ planes, as shown in Fig. 4. Unit cell A was subjected to monotonic loading in the $X$ direction and the results were compared with the experimental results (Ogasawara et al., 2004). Unit cell B was loaded along the $X\left(0^{\circ}\right), Y\left(90^{\circ}\right)$, and $45^{\circ}$ directions to evaluate the micromechanical model with the experimental results presented in this study.

In the micromechanical model, the stiffness of the unit cell and the stresses in each fiber bundle were calculated using three-dimensional laminate theory, (Gudmundson and Zang, 1993) which assumes that the in-plane strain and the outof-plane stress in each ply are spatially equal to the applied laminate in-plane strain and out-of-plane stress. As shown in Fig. 2 (b) and Fig. 3 (b), unit cells A and B are divided into three regions along the $\mathrm{X}$ direction. Three regions $(\mathrm{E}, \mathrm{F}$, and $\mathrm{G})$ are further divided into subcomponents, as shown in Fig. 2 (c) and Fig. 3 (c). By applying three-dimensional 


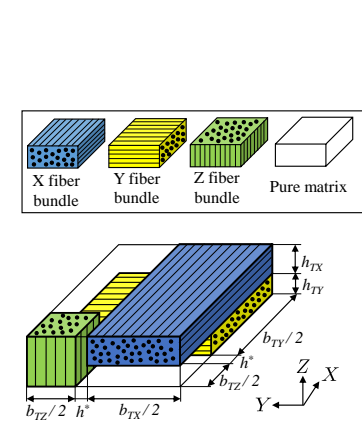

(a)

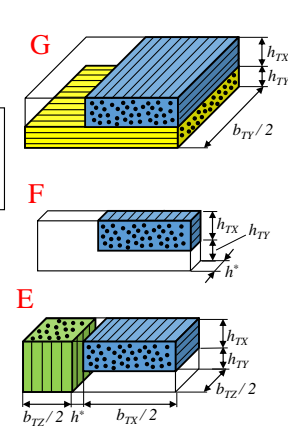

(b)

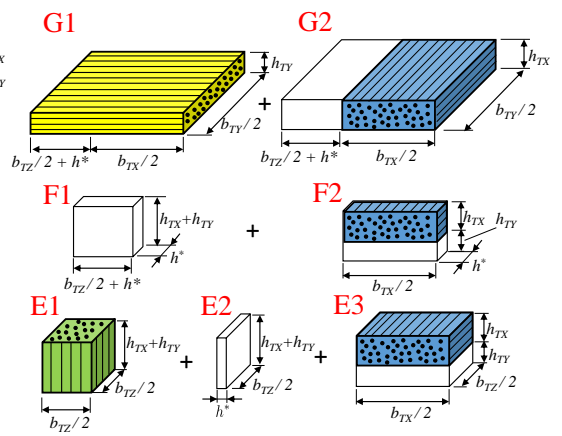

(c)

Figure 3. Schematic representations of (a) unit cell B, (b) components of unit cell B and (c) subcomponents of regions $\mathrm{E}, \mathrm{F}$, and $\mathrm{G}$.

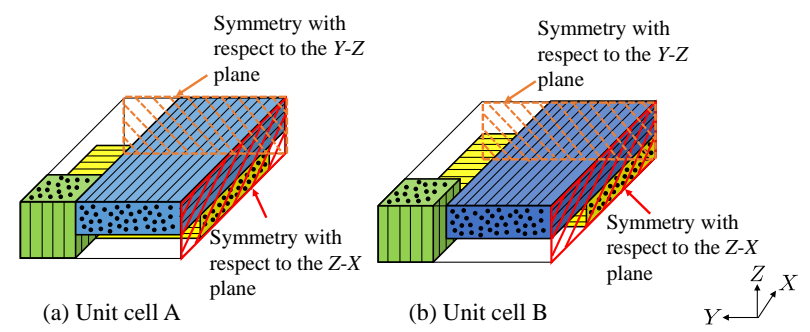

Figure 4. Symmetric condition.

laminate theory, the compliance of unit cell A was calculated by carrying out three steps: (1) the compliances of subcomponents E2, F2, and G2 were calculated by stacking the $X$-direction fiber bundle and pure matrix in the $Y$ or $Z$ direction; (2) the compliance of components $\mathrm{E}, \mathrm{F}$, and $\mathrm{G}$ was computed by laminating the subcomponents in the $Y$ or $Z$ direction; (3) the compliance of unit cell A was determined by stacking components $\mathrm{E}$, $\mathrm{F}$ and $\mathrm{G}$ in the $X$ direction. The compliance of unit cell B was calculated in the same manner. The stresses in each fiber bundle and the pure matrix were calculated using the division order depicted in Figs. 2 and 3. These fiber bundle stresses were used to calculate the crack density of the transverse cracks perpendicular to the $X$ axis in the $Y$ - and $Z$ direction fiber bundles and the matrix crack density in the $X$-fiber bundle. In the case of unit cell $\mathrm{B}$, the crack density of transverse cracks perpendicular to the $Y$ axis in the $X$ - and $Z$-direction fiber bundles and the matrix crack density in the $Y$-direction fiber bundle were computed by calculating the fiber bundle stresses according to the dividing sequence, as shown in Fig. 5. Unit cell B is divided into three components (H, I and J) in the $Y$ direction; these components were further divided into subcomponents. 

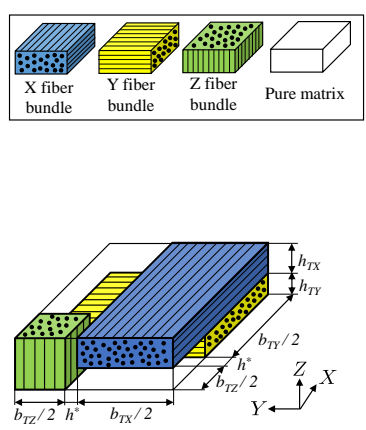

(a)
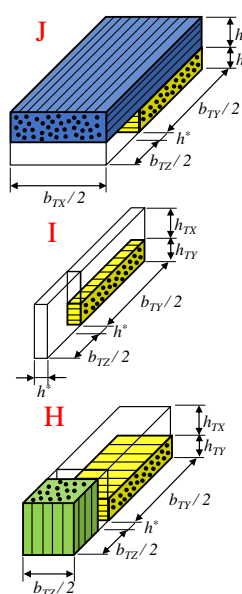

(b)
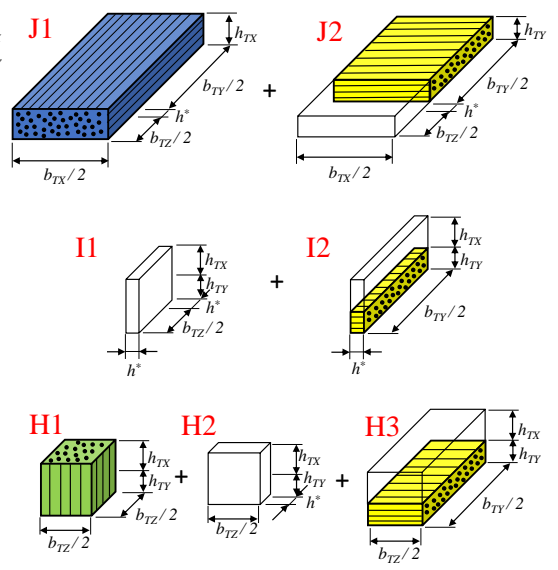

(c)

Figure 5. Schematic representations of (a) unit cell B, (b) components of unit cell B and (c) subcomponents of regions $\mathrm{H}, \mathrm{I}$, and $\mathrm{J}$.

The effective compliance of the fiber bundles with transverse and matrix cracking is represented based on CDM. In this study, the effective compliance proposed by Lopes et al. (Lopes et al., 2009) is used. According to them, the complementary free energy density, $U_{c}$, of the damaged fiber bundles in the material coordinate system $(1,2,3)$ is defined as

$$
\begin{aligned}
U_{c} & =\frac{\sigma_{11}^{2}}{2\left(1-d_{1}^{\mathrm{L}}\right)\left(1-d_{1}^{\mathrm{TI}}\right)\left(1-d_{1}^{\mathrm{TO}}\right) E_{1}^{\mathrm{FB}}} \\
& +\frac{1}{2 E_{2}^{\mathrm{FB}}}\left[\frac{\sigma_{22}^{2}}{2\left(1-d_{2}^{\mathrm{L}}\right)\left(1-d_{2}^{\mathrm{TI}}\right)\left(1-d_{2}^{\mathrm{TO}}\right)}+\frac{\sigma_{33}^{2}}{2\left(1-d_{3}^{\mathrm{L}}\right)\left(1-d_{3}^{\mathrm{TI}}\right)\left(1-d_{3}^{\mathrm{TO}}\right)}\right] \\
& -\frac{\nu_{12}^{F B}}{E_{1}^{F B}}\left(\sigma_{22}+\sigma_{33}\right) \sigma_{11}-\frac{\nu_{23}^{F B}}{E_{2}^{F B}} \sigma_{22} \sigma_{33} \\
& +\frac{\sigma_{12}^{2}}{2\left(1-d_{6}^{\mathrm{L}}\right)\left(1-d_{6}^{\mathrm{TI}}\right)\left(1-d_{6}^{\mathrm{TO}}\right) G_{12}^{\mathrm{FB}}} \\
& +\frac{\sigma_{13}^{2}}{2\left(1-d_{5}^{\mathrm{L}}\right)\left(1-d_{5}^{\mathrm{TI}}\right)\left(1-d_{5}^{\mathrm{TO}}\right) G_{12}^{\mathrm{FB}}} \\
& +\frac{\sigma_{23}^{2}}{2\left(1-d_{4}^{\mathrm{L}}\right)\left(1-d_{4}^{\mathrm{TI}}\right)\left(1-d_{4}^{\mathrm{TO}}\right) G_{23}^{\mathrm{FB}}}
\end{aligned}
$$

Subscripts 1, 2, and 3 denote the fiber, in-plane transverse, and out-of-plane transverse directions, respectively. The superscript FB represents the property of the fiber bundle, $E$ is Young's modulus, $G$ is the shear modulus, and $\nu$ is Poisson's ratio. The elastic moduli of the fiber bundle were calculated by the model proposed by Kravchenko et 
al. (see Appendix A in their article (Kravchenko et al., 2016)) using the elastic moduli of the fiber and matrix. The damage variable, $d$, describes the stiffness reduction of the mechanical properties due to damage. The superscripts L, TI, and TO denote reductions due to damage perpendicular to axes 1,2 , and 3, respectively. The following expression are assumed to consider the fiber bundle with matrix cracks perpendicular to axis 1 and the transverse cracks perpendicular to axes 2 and 3

$$
\begin{gathered}
d_{1}^{\mathrm{TI}}=d_{1}^{\mathrm{TO}}=d_{2}^{\mathrm{L}}=d_{2}^{\mathrm{TO}}=d_{3}^{\mathrm{L}}=d_{3}^{\mathrm{TI}}=d_{6}^{\mathrm{TO}}=d_{5}^{\mathrm{TI}}=d_{4}^{\mathrm{L}}=0, \\
\frac{1}{1-d_{5}^{\mathrm{L}}}=\frac{1}{1-d_{6}^{\mathrm{L}}}=\frac{1}{2}\left[\frac{1}{1-d_{1}^{\mathrm{L}}}+\right], \\
\frac{1}{\left(1-d_{4}^{\mathrm{TI}}\right)\left(1-d_{4}^{\mathrm{TO}}\right)}=\frac{1}{2}\left[\frac{1}{1-d_{2}^{\mathrm{TI}}}+\frac{1}{1-d_{3}^{\mathrm{TO}}}\right] .
\end{gathered}
$$

Equations (3) and (4) represent the approximation formulae proposed by Chou and $\mathrm{Lu}$ (Chow and Lu, 1989). Using Eqs. (1) and (2), the effective compliance of the damaged bundle can be represented as follows.

$$
\begin{aligned}
& \boldsymbol{S}^{\mathrm{FB}}=\frac{\partial^{2} U_{c}}{\partial \boldsymbol{\sigma} \otimes \partial \boldsymbol{\sigma}} \\
& =\left[\begin{array}{ccc}
\frac{1}{\left(1-d_{1}^{L}\right) E_{1}^{\mathrm{FB}}} & -\frac{\nu_{12}^{\mathrm{FB}}}{E_{1}^{\mathrm{FB}}} & -\frac{\nu_{12}^{\mathrm{FB}}}{E^{\mathrm{FB}}} \\
& \frac{1}{\left(1-d_{2}^{1 \mathrm{~T}}\right) E_{2}^{\mathrm{FB}}} & -\frac{\nu_{23}^{\mathrm{B}}}{E^{\mathrm{FB}}} \\
& & \frac{1}{\left(1-d_{3}^{\mathrm{TO}}\right) E_{2}^{\mathrm{FB}}} \\
& & \\
\text { sym. } & &
\end{array}\right. \\
& \left.\begin{array}{ccc}
0 & 0 & 0 \\
0 & 0 & 0 \\
0 & 0 & 0 \\
1 & 0 & 0 \\
\frac{1}{\left(1-d_{4}^{\mathrm{TI}}\right)\left(1-d_{4}^{\mathrm{TO}}\right) G_{23}^{\mathrm{FB}}} & \frac{1}{\left(1-d_{5}^{\mathrm{L}}\right)\left(1-d_{5}^{\mathrm{TO}}\right) G_{12}^{\mathrm{FB}}} & \frac{1}{\left(1-d_{6}^{\mathrm{L}}\right)\left(1-d_{6}^{\mathrm{TI}}\right) G_{12}^{\mathrm{FB}}}
\end{array}\right] .
\end{aligned}
$$

The effective compliance matrix can reproduce the effective stiffness in composite laminates with transverse cracking and fiber breakage (Onodera and Okabe, 2020). However, in the Lopes model, damage variables indicate the knockdown factors for elastic constants, and only the orthogonal components of the damage tensor were utilized. The effective matrix considering the full matrix of the damage tensor is available in the literature (Voyiadjis and Kattan, 2006). The sophisticated model for effective compliance matrix (Voyiadjis and Kattan, 2006) can be used by formulating the full matrix of the damage tensor, which is a future work prospect. 
The damage variables associated with transverse cracking can be formulated based on micromechanics. According to Onodera and Okabe, (Onodera and Okabe, 2020) damage variables $d_{22}^{\mathrm{TI}}, d_{12}^{\mathrm{TI}}, d_{33}^{\mathrm{TO}}$, and $d_{31}^{\mathrm{TO}}$ are expressed as functions of transverse crack density:

$$
\begin{aligned}
d_{22}^{\mathrm{TI}}\left(\rho_{k}^{\mathrm{TI}}\right) & =\frac{\lambda h_{\text {thick }} \rho_{k}^{\mathrm{TI}}}{\sqrt{3}} \tanh \left[\frac{\sqrt{3}}{\lambda h_{\text {thick }} \rho_{k}^{\mathrm{TI}}}\right], \\
d_{12}^{\mathrm{TI}}\left(\rho_{k}^{\mathrm{TI}}\right) & =\frac{h_{\text {thick }} \rho_{k}^{\mathrm{TI}}}{\sqrt{3}} \tanh \left[\frac{\sqrt{3}}{h_{\text {thick }} \rho_{k}^{\mathrm{TI}}}\right], \\
d_{33}^{\mathrm{TO}}\left(\rho_{k}^{\mathrm{TO}}\right) & =\frac{\lambda b_{\text {width }} \rho_{k}^{\mathrm{TO}}}{\sqrt{3}} \tanh \left[\frac{\sqrt{3}}{\lambda b_{\text {width }} \rho_{k}^{\mathrm{TO}}}\right], \\
d_{31}^{\mathrm{TO}}\left(\rho_{k}^{\mathrm{TO}}\right) & =\frac{b_{\text {width }} \rho_{k}^{\mathrm{TO}}}{\sqrt{3}} \tanh \left[\frac{\sqrt{3}}{b_{\text {width }} \rho_{k}^{\mathrm{TO}}}\right], \\
\lambda & =\sqrt{\frac{E_{2}^{\mathrm{FB}}-G_{23}^{\mathrm{FB}}\left(\nu_{23}^{\mathrm{FB}}+\nu_{12}^{\mathrm{FB}} \nu_{21}^{\mathrm{FB}}\right)}{G_{23}^{\mathrm{FB}}\left(1-\nu_{12}^{\mathrm{FB}} \nu_{21}^{\mathrm{FB}}\right)}},
\end{aligned}
$$

where $h_{\text {thick }}$ is the fiber bundle thickness, and $b_{\text {width }}$ is the fiber bundle width, while $\rho_{k}^{\mathrm{T} j}$ $(j=\mathrm{I}, \mathrm{O} ; k=X, Y, Z)$ is the transverse crack density in the $k$-direction fiber bundle. The evolution of the transverse crack density was described as a function of the applied loading using both strength and energy criteria. It is assumed that the quadratic criterion induced microcracks perpendicular to axis 2 in the k-direction fiber bundle:

$$
\left(\frac{\sigma_{22}^{k}}{\sigma_{22 c}^{k}}\right)^{2}+\left(\alpha_{k}^{\mathrm{TI}} \frac{\sigma_{12}^{k}}{\sigma_{22 c}^{k}}\right)^{2}+\left(\beta_{k}^{\mathrm{TI}} \frac{\sigma_{23}^{k}}{\sigma_{22 c}^{k}}\right)^{2} \geq 1 .
$$

In the same way, microcracks perpendicular to axis 3 are initiated by the following criterion:

$$
\left(\frac{\sigma_{33}^{k}}{\sigma_{33 c}^{k}}\right)^{2}+\left(\alpha_{k}^{\mathrm{TO}} \frac{\sigma_{23}^{k}}{\sigma_{33 c}^{k}}\right)^{2}+\left(\beta_{k}^{\mathrm{TO}} \frac{\sigma_{31}^{k}}{\sigma_{33 c}^{k}}\right)^{2} \geq 1 .
$$

Superscript/subscript $k$ denotes the property of the $k$-direction fiber bundle, $\sigma_{i j}$ is the stress, and $\sigma_{i j c}$ represents a critical stress. The stress $\sigma_{i j}^{k}$ of the $k$-direction fiber bundles was calculated using three dimensional laminate theory. The constants $\alpha$ and $\beta$ are mixed-mode ratios for the contribution to shear stress defined as follows:

$$
\alpha_{k}^{\mathrm{TI}}=\frac{\sigma_{22 c}^{k}}{\sigma_{12 c}^{k}}, \quad \beta_{k}^{\mathrm{TI}}=\frac{\sigma_{22 c}^{k}}{\sigma_{23 c}^{k}}, \quad \alpha_{k}^{\mathrm{TO}}=\frac{\sigma_{33 c}^{k}}{\sigma_{23 c}^{k}}, \quad \beta_{k}^{\mathrm{TO}}=\frac{\sigma_{33 c}^{k}}{\sigma_{31 c}^{k}} .
$$

The microcracks propagate into transverse cracks when the following energy criterion is satisfied:

$$
\Gamma^{k} \geq \Gamma_{c}^{k}
$$


The variable $\Gamma^{k}$ is the energy release rate associated with the propagation of transverse cracking in the $k$-direction fiber bundle, and $\Gamma_{c}^{k}$ is the critical energy release rate of the $k$ direction fiber bundle. A new transverse crack is assumed to propagate between the two pre-existing cracks and over the full width and thickness of the $k$-direction fiber bundle under a constant applied stress of component $p(p=\mathrm{E}, \mathrm{F}, \mathrm{G}, \mathrm{H}, \mathrm{J})$ in the bundle. Under this assumption, the energy release rate $\Gamma^{k}$ is formulated as: (Onodera and Okabe, 2019)

$$
\Gamma^{k}\left(\rho_{k}^{\text {trans }}\right)=-\frac{U^{p}\left(\rho_{k}^{\text {trans }} / 2\right)-2 U^{p}\left(\rho_{k}^{\text {trans }}\right)}{A^{\text {trans }}}, \quad \text { trans }=\mathrm{TI}, \mathrm{TO},
$$

where $A^{\text {trans }}\left(=A^{\mathrm{TI}}=b_{\text {len }} h_{\text {thick }}\right.$ or $\left.A^{\mathrm{TO}}=b_{\text {width }} b_{\text {len }}\right)$ is the surface area of the transverse crack and $b_{\text {len }}$ is the fiber bundle length. Additionally, $U^{p}$ is the strain energy in a component $p$ with length $1 / \rho_{k}^{\text {trans }}$ as follows:

$$
U^{p}\left(\rho_{k}^{\text {trans }}\right)=\frac{A_{U 1}^{\text {trans }}}{2 \rho_{k}^{\text {trans }}}\left(\boldsymbol{\sigma}^{p}\right)^{\mathrm{T}} \boldsymbol{S}^{p} \boldsymbol{\sigma}^{p}, \quad \text { trans }=\mathrm{TI}, \mathrm{TO},
$$

with

$$
A_{U 1}^{\mathrm{TI}}=b_{p \mathrm{~T}} t_{p}, A_{U 1}^{\mathrm{TO}}=b_{p \mathrm{~L}} t_{p},
$$

where $t_{p}, b_{p \mathrm{~T}}, b_{p \mathrm{~L}}, \boldsymbol{\sigma}^{p}$, and $\boldsymbol{S}^{p}$ are the thickness, width, length, average stress, and compliance matrix of component $p$, respectively. The average stress $\boldsymbol{\sigma}^{p}$ was obtained using three-dimensional laminate theory. In this study, the transverse crack density increased as the stress- and energy-based criteria became being satisfied.

Damage variables, $d_{11}^{\mathrm{L}}$, related to matrix cracking parallel to axis 1 in the fiber bundle can be expressed as:

$$
d_{11}^{\mathrm{L}}=1-\frac{E_{1 \mathrm{dam}}^{\mathrm{FB}}}{E_{1}^{\mathrm{FB}}}
$$

where $E_{1 \text { dam }}^{\mathrm{FB}}$ denotes the effective longitudinal Young's modulus of the $k$-direction fiber bundle. When the average bundle stress, $\sigma_{11}^{k}$, is applied to the $k$-direction bundle along the 1 -axis, the average bundle strain, $\varepsilon_{11}^{\text {ave }}$, along this axis, which disregards the additional displacement caused by matrix cracking, is expressed as

$$
\varepsilon_{11}^{\text {ave }}=\frac{\sigma_{11}^{k}}{E_{1}^{\mathrm{FB}}} .
$$

In addition, the $k$-direction bundle strain $\varepsilon_{11}^{k}$, which considers the incremental displacement caused matrix cracking, can be described as

$$
\varepsilon_{11}^{k}=\frac{\sigma_{11}^{k}}{E_{1 \mathrm{dam}}^{\mathrm{FB}}} .
$$

Substituting Eqs. (19) and (20) into Eq. (18), the damage variable, $d_{11}^{L}$, is rewritten as

$$
d_{11}^{\mathrm{L}}=1-\frac{\varepsilon_{11}^{\mathrm{ave}}}{\varepsilon_{11}^{k}}=1-\frac{\sigma_{11}^{k} / E_{1}^{\mathrm{FB}}}{\varepsilon_{11}^{k}}
$$


From the Curtin model, (Curtin et al., 1998; Curtin, 2000) the axial fiber bundle strain $\varepsilon_{11}^{k}$, considering additional strain due to matrix cracking and fiber breaks, is given by:

$$
\begin{aligned}
\varepsilon_{11}^{k} & =\frac{\sigma_{11}^{k}}{E_{1}^{\mathrm{FB}}}+\frac{a}{\Lambda^{k} E_{f}} \frac{\left(\sigma_{11}^{k}-\sigma_{\mathrm{deb}}^{k}\right)\left(\sigma_{11}^{k}+\sigma_{\mathrm{deb}}^{k}\right)}{\sigma_{\mathrm{R}}^{k}-\sigma_{\mathrm{deb}}^{k}}\left(1-e^{-N^{k}\left(\bar{\sigma}_{11}^{k}, L, A\right)}\right) \\
& +\frac{1}{E_{f}}\left(T_{f}^{k}-\frac{\sigma_{11}^{k}}{V_{f}}\right) \frac{2 \delta^{k}}{\bar{x}^{k}}\left(\bar{x}^{k}>2 \delta^{k}\right), \\
\varepsilon_{11}^{k} & =\frac{\sigma_{11}^{k}}{V_{f} E_{f}}-\frac{a \Lambda^{k}}{4 E_{f}}\left(\sigma_{\mathrm{R}}^{k}-\sigma_{\mathrm{deb}}^{k}\right)\left(1-e^{-N^{k}\left(\bar{\sigma}_{11}^{k}, L, A\right)}\right)^{-1} \\
& +\frac{1}{E_{f}}\left(T_{f}^{k}-\frac{\sigma_{11}^{k}}{V_{f}}\right) \quad\left(\bar{x}^{k}<2 \delta^{k}\right) .
\end{aligned}
$$

Coefficient $a$, slip length $\delta^{k}$ generated by fiber/matrix debonding around matrix cracking, the average matrix crack spacing $\bar{x}^{k}$, and the number of flaws $N^{k}$ in an observed length $L$ and area $A$ that can propagate at applied stress are given by:

$$
\begin{aligned}
a & =\frac{\left(1-V_{f}\right) E_{m}}{V_{f} E_{1}^{\mathrm{FB}}} \text { with } E_{1}^{\mathrm{FB}}=V_{f} E_{f}+\left(1-V_{f}\right) E_{m}, \\
\delta^{k} & =\frac{a r}{2 \tau^{k}}\left(\sigma_{11}^{k}-\sigma_{\mathrm{deb}}^{k}\right), \quad \delta_{\mathrm{R}}^{k}=\frac{a r}{2 \tau^{k}}\left(\sigma_{\mathrm{R}}^{k}-\sigma_{\mathrm{deb}}^{k}\right), \\
\bar{x}^{k} & =\bar{x}_{s}^{k}\left(1-e^{-N^{k}\left(\bar{\sigma}_{11}^{k}, L, A\right)}\right)^{-1} \text { with } \bar{x}_{s}^{k}=\Lambda^{k} \delta_{\mathrm{R}}^{k} \\
N^{k}\left(\bar{\sigma}_{11}^{k}, L, A\right) & =\frac{L A}{2 \delta_{\mathrm{R}} A_{0}}\left(\frac{\bar{\sigma}_{11}^{k}-\sigma_{11 i}^{k}}{\sigma_{\mathrm{R}}^{k}-\sigma_{11 i}^{k}}\right)^{m_{1}^{k}}
\end{aligned}
$$

where $r$ is the fiber radius, $V_{f}$ is the fiber volume fraction, $\tau$ is the sliding stress at the fiber/matrix interface, $E_{f}$ is the Young's modulus of the fiber, $E_{m}$ is the Young's modulus of the matrix, $\bar{x}_{s}^{k}$ is the saturated matrix crack spacing, $\delta_{\mathrm{R}}^{k}$ is the critical slip length associated with the critical matrix cracking stress $\sigma_{\mathrm{R}}^{k}, A_{0}$ is the reference area, $\sigma_{11 i}^{k}$ is the minimum cracking stress, $m_{1}^{k}$ is the Weibull modulus for matrix cracking, and $\sigma_{\text {deb }}^{k}$ is the debonding stress introduced by Hutchinson and Jensen (Hutchinson and Jensen, 1990). The term $\bar{\sigma}_{11}^{k}$ is the effective stress considering the mixed-mode matrix crack progression introduced in this study. It is assumed that the following quadratic criterion induced matrix cracks:

$$
\left(\frac{\sigma_{11}^{k}}{\sigma_{11 i}^{k}}\right)^{2}+\left(\alpha_{k}^{\mathrm{L}} \frac{\sigma_{12}^{k}}{\sigma_{11 i}^{k}}\right)^{2}+\left(\beta_{k}^{\mathrm{L}} \frac{\sigma_{13}^{k}}{\sigma_{11 i}^{k}}\right)^{2} \geq 1,
$$

with

$$
\alpha_{k}^{\mathrm{L}}=\frac{\sigma_{11 i}^{k}}{\sigma_{12 i}^{k}}, \quad \beta_{k}^{\mathrm{L}}=\frac{\sigma_{11 i}^{k}}{\sigma_{13 i}^{k}},
$$

where $\sigma_{12 i}^{k}$ and $\sigma_{13 i}^{k}$ are the minimum in-plane and out-of-plane shear cracking stresses calculated from the energy-based criteria, (Aveston et al., 1971; Rajan and Zok, 2014) 
respectively. To evaluate the left expression of Eq. (28), the effective stress, $\bar{\sigma}_{11}^{k}$, is defined as follows:

$$
\frac{\bar{\sigma}_{11}^{k}}{\sigma_{11 i}^{k}} \equiv \sqrt{\left(\frac{\sigma_{11}^{k}}{\sigma_{11 i}^{k}}\right)^{2}+\left(\alpha_{k}^{\mathrm{L}} \frac{\sigma_{12}^{k}}{\sigma_{11 i}^{k}}\right)^{2}+\left(\beta_{k}^{\mathrm{L}} \frac{\sigma_{13}^{k}}{\sigma_{11 i}^{k}}\right)^{2}} .
$$

The stress $\sigma_{i j}^{k}$ of the $k$-direction fiber bundles was calculated using three dimensional laminate theory. Using Eq. (30), the number of flows $N^{k}$ considering mixed-mode matrix cracking is calculated. $\Lambda^{k}=\Lambda^{k}\left(m_{1}^{k}, \sigma_{11 i}^{k} / \sigma_{\mathrm{R}}^{k}, \sigma_{\mathrm{deb}}^{k} / \sigma_{\mathrm{R}}^{k}\right)$ in Eqs. (23) and (26) is the matrix cracking spacing parameter as a function of the Weibull modulus, the minimum cracking stress, the critical matrix cracking stress, and the debonding stress; $\Lambda^{k}$ has been previously reported (Curtin et al., 1998; Curtin, 2000) and its minimum value is 1.337 (Curtin, 1993). The term $T_{f}^{k}$ is the stress carried by the unbroken fibers, which is determined by solving the following nonlinear equation:

$$
f_{1}\left(T_{f}^{k}\right) \equiv\left(1-q\left(z_{0}^{k}, T_{f}^{k}\right)\left(1+\frac{2 l_{s}^{k}}{\bar{x}^{k}}\right)\right) T_{f}^{k}-\frac{\sigma_{11}^{k}}{V_{f}}=0,
$$

where

$$
\begin{aligned}
z_{0}^{k} & =\left\{\begin{array}{cc}
\delta^{k} & \left(\bar{x}^{k}>2 \delta^{k}\right) \\
\bar{x}^{k} / 2 & \left(\bar{x}^{k}<2 \delta^{k}\right)
\end{array}\right. \\
q\left(z_{0}^{k}, T_{f}^{k}\right) & =1-\exp \left[-\left\{1-\left(1-\frac{z_{0}^{k}}{l_{s}^{k}}\right)^{m_{2}}\right\}\left(\frac{T_{f}^{k}}{\sigma_{c}}\right)^{m_{2}+1} \frac{1}{m_{2}+1}\right] .
\end{aligned}
$$

In this equation, $l_{s}^{k}\left(=r T_{f}^{k} /\left(2 \tau^{k}\right)\right)$ is the fiber slip length around fiber breakage, $q\left(z_{0}^{k}, T_{f}^{k}\right)$ is the probability that the fiber will fail within $z_{0}^{k}$ at/below stress $T_{f}^{k}, m_{2}$ is the Weibull modulus for fiber breakage, and $\sigma_{c}$ is the characteristic fiber strength. The values of $m_{2}$ and $\sigma_{c}$ can be obtained by fiber fracture mirror observation (Davies et al., 1999; Thouless et al., 1989). The ultimate failure condition of the fiber bundle is given by:

$$
\frac{d f_{1}}{d T_{f}^{k}}=0
$$

In this study, when the failure condition (34) is satisfied, the 3D woven composite is regarded as having failed and its ultimate strength and failure strain are obtained.

This study considered the stress redistribution between fiber bundles resulting from the fiber/matrix interfacial debonding associated with matrix cracking. As shown in Fig. 6, fiber/matrix interfacial debonding with slip length $2 \delta^{k}$ around a matrix crack occurs when the crack is initiated. In the debonding region, fibers in the $k(=X, Y, Z)$ direction fiber bundle mainly carry the applied load upon matrix cracking. Therefore, the load-bearing capacity of the $q(q \neq k)$ direction fiber bundles and pure matrix next to the debonding region in the $k$-direction fiber bundle is highly reduced owing to debonding. This effect is 


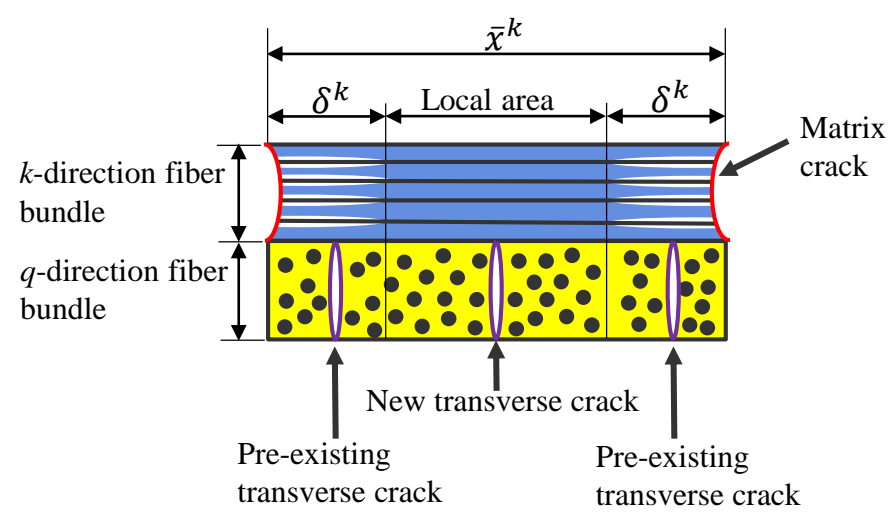

Figure 6. Stress redistribution between $k$-and $q$-direction fiber bundles due to the fiber/matrix interfacial debonding associated with matrix cracking.

required to accurately predict the stress-strain response and transverse crack progression of a 3D woven CMC. It is assumed that the $q$-direction fiber bundles and pure matrix adjacent to the fiber/matrix interfacial debonding with length, $2 \delta^{k}$, in the $k$-direction fiber bundle do not bear the applied load. Under this assumption, the stiffness reduction $V_{\mathrm{del}}^{k}$ caused by fiber/matrix debonding in the $k$-direction fiber bundle is given by:

$$
V_{\mathrm{del}}^{k}=\frac{\bar{x}^{k}-2 \delta^{k}}{\bar{x}^{k}} .
$$

The stiffness reduction caused by debonding is considered to multiply $V_{\mathrm{del}}^{k}$ and the stiffness matrix of the $q$-direction fiber bundles and pure matrix. The transverse crack densities considering debonding are calculated using the following steps. First, the transverse crack density $\rho_{q \text {, local }}^{\text {trans }}$ (trans $=$ TI, TO) in a local area with length $\bar{x}^{k}-2 \delta^{k}$, where the $q$-direction fiber bundle has load-bearing capacity, is calculated from the stress (Eqs. (11) and (12)) and energy (Eq. (14)) criteria, respectively. Then, the transverse crack density in the $q$-direction fiber bundle is calculated by adding the number of new cracks propagated in the local region to the number of pre-existing cracks as follows:

$$
\rho_{q}^{\text {trans }, n}=\rho_{q}^{\text {trans }, n-1}+V_{\text {del }}^{k}\left(\rho_{q, \text { local }}^{\text {trans }, n}-\rho_{q}^{\text {trans }, n-1}\right), \quad \text { trans }=\text { TI or TO },
$$

where $n$ is the current incremental step and $n-1$ is the previous incremental step. The transverse crack density in the $q$-direction fiber bundle is saturated when debonding in the $k$-direction fiber bundle has fully propagated $\left(V_{\mathrm{del}}^{k}=0\right)$. An analysis flowchart for calculating the nonlinear stress-strain response of a 3D woven CMC subjected to inplane loading is shown in Fig. 7, and the the algorithm for progressively analyzing transverse cracking perpendicular to axis 2 is depicted in Fig. 8. Transverse cracking perpendicular to axis 3 is progressively analyzed in the same manner as shown in Fig. 8. 


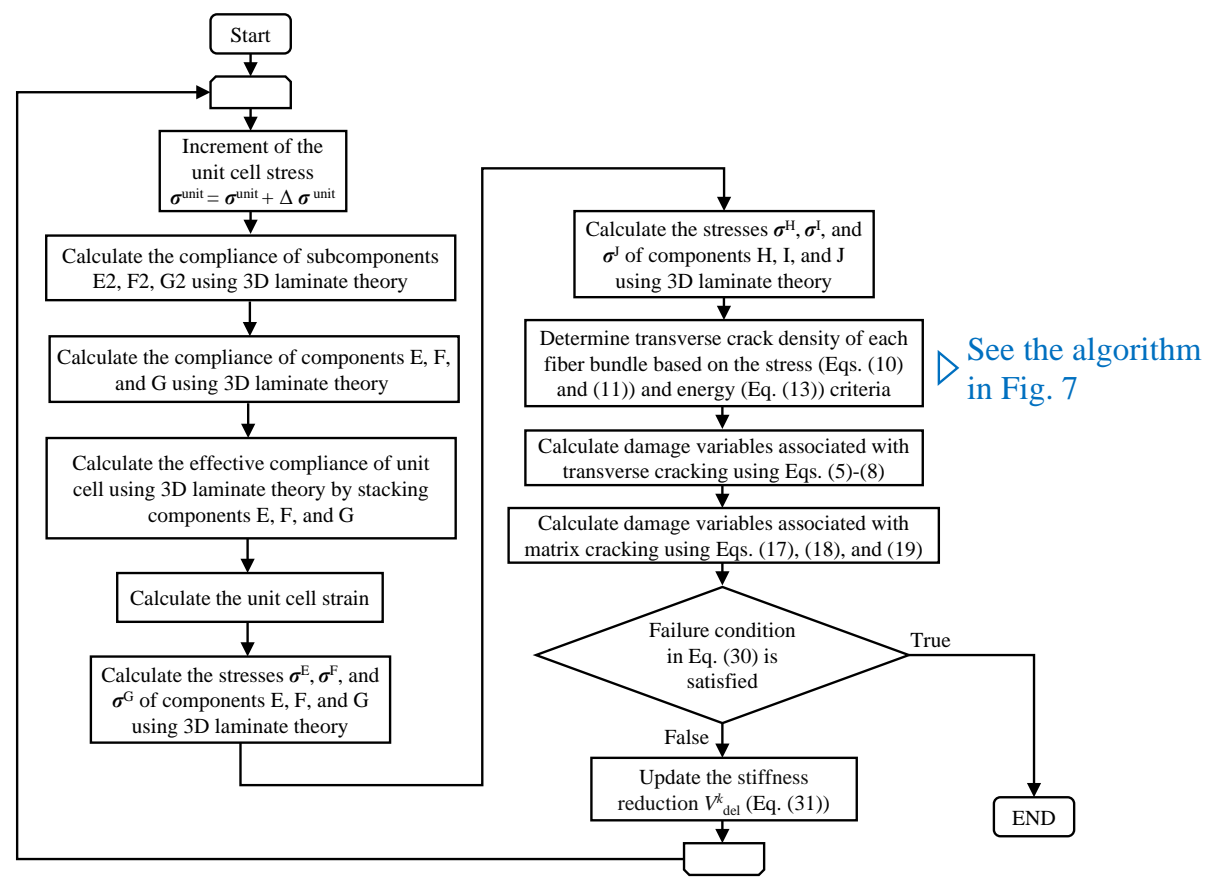

Figure 7. Analysis flowchart for calculating the nonlinear stress-strain response of a 3D woven CMC subjected to in-plane loading.

\section{Mesomechanical model}

To validate the micromechanical model, the mesomechanical model was established using FEA and CDM. The micromechanical model does not consider stress disturbance caused by the geometry of the unit cell, whereas the mesomechanical model considers this effect. Therefore, the simulated results by the mesomechanical model are more accurate than those obtained by micromechanical model. Displacement controlled static analysis via 3D FEA was used to consider the stress disturbance due to the structural geometry of the 3D woven composite under $X$ - and $Y$-direction tensile loads. Figure 9 shows FEA models for the 3D woven unit cells with approximately 17000 eight-node brick elements, which are called C3D8 in ABAQUS (ABAQUS, 2013). The following boundary condition was employed for $X$-direction tensile loading:

$$
u=0 \text { on } x=0, \quad v=w=0 \text { at } x=y=z=0, \quad u=u_{\text {app }} \text { on } x=L_{X},
$$

and for $Y$-direction tensile loading:

$$
v=0 \text { on } y=0, \quad u=w=0 \text { at } x=y=z=0, \quad v=v_{\text {app }} \text { on } y=L_{Y} .
$$




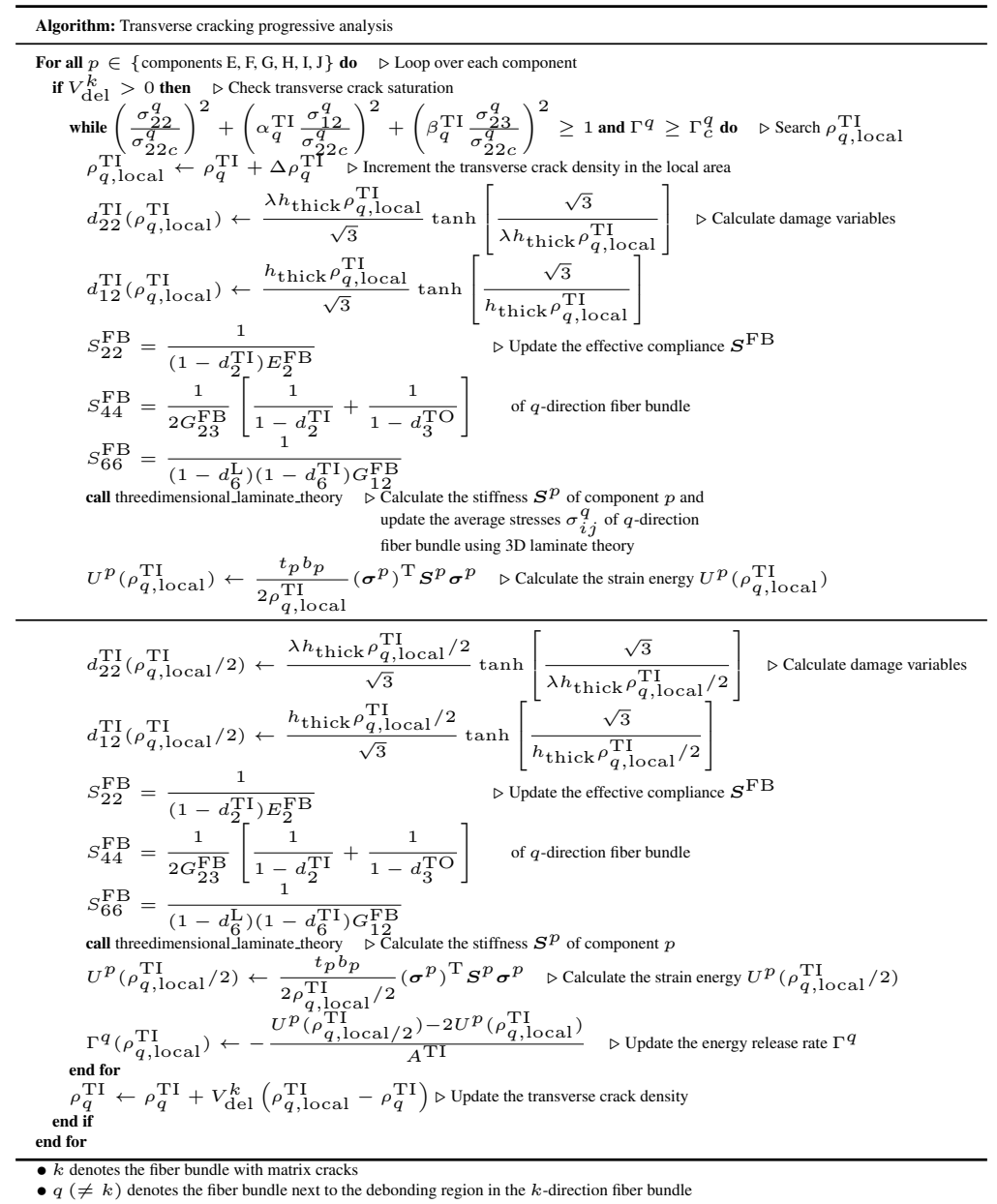

Figure 8. Algorithm for progressively analyzing transverse cracking perpendicular to axis 2 .

The variable $L_{j}(j=X, Y, Z)$ is the unit cell length parallel to the $j$-direction, and $u, v$, and $w$ are the displacements in the $X$-, $Y$-, and $Z$-directions, respectively. The subscript "app" represents the applied displacement.

The matrix or transverse cracks in fiber bundles were considered using the CDM. The effective compliance $\boldsymbol{S}^{\mathrm{FB}}$ of the damaged fiber bundle in Eq. (5) and the shear damage variables in Eqs. (3) and(4) were employed. The damage state of an element with transverse cracks (or matrix cracks) in the fiber bundle is assumed to be the same as that of the fiber bundles possessing steady-state transverse (or matrix) cracks propagating throughout the width and thickness of the fiber bundle. The damage variables in Eqs. (6)-(9) associated with transverse cracking were used, and the transverse cracks in the 


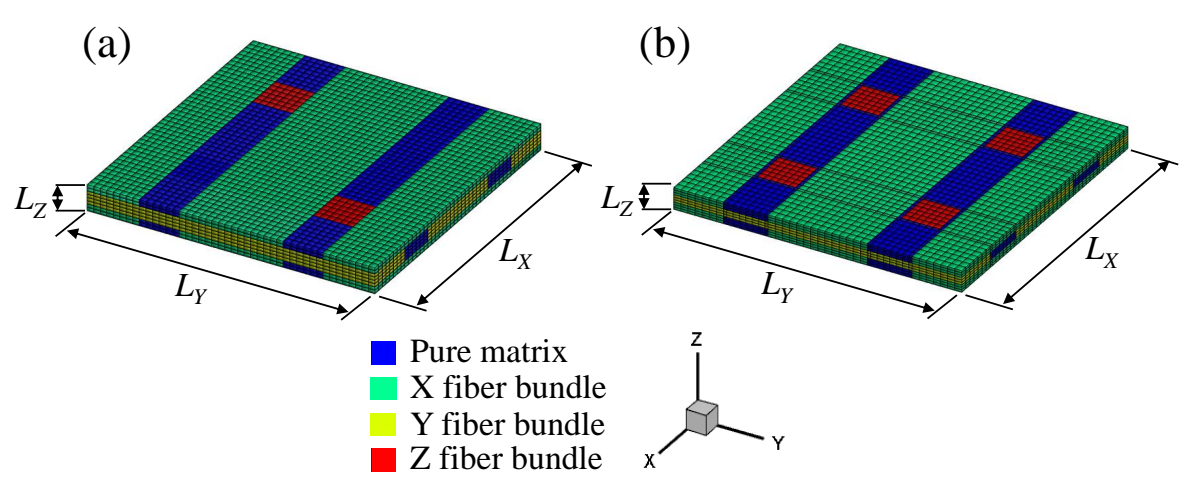

Figure 9. Finite element model for 3D woven structures of (a) unit cell $A$ and (b) unit cell $B$.

local area (Fig. 6) were progressively analyzed in the following four steps. (1) The transverse crack density $\rho_{q \text {, local }}^{\text {trans }}$ (trans $=$ TI or TO) of each element of the $q$-direction $(q=X, Y, Z)$ fiber bundle in the local area was initialized to $\rho_{q, \text { local }}^{\text {trans }}=\rho_{q}^{\text {trans, } n-1}+\Delta \rho$ with the increment $\Delta \rho$ and the transverse crack density $\rho_{q}^{\text {trans, } n-1}$ at the previous step. (2) The stress criterion (Eq. (11) or (12)) was checked for each element with transverse crack density $\rho_{q, \text { local }}^{\text {trans }}$. (3) When the stress criterion was satisfied, the energy release rate $\Gamma^{k}\left(\rho_{q, \text { local }}^{\text {trans }}\right)$ under constant strains was calculated using the following equation:

$$
\Gamma^{k}\left(\rho_{q, \text { local }}^{\text {trans }}\right)=\frac{U^{\mathrm{FB}}\left(\rho_{q, \text { local }}^{\text {trans }} / 2\right)-2 U^{\mathrm{FB}}\left(\rho_{q, \text { local }}^{\text {trans }}\right)}{A^{\text {trans }}}, \quad \text { trans }=\text { TI or TO }
$$

where $A^{\text {trans }}\left(=A^{\mathrm{TI}}=b_{\text {len }} h_{\text {thick }}\right.$ or $\left.A^{\mathrm{TO}}=b_{\text {width }} b_{\text {len }}\right)$ is the surface area of the transverse cracking in the fiber bundle with length $b_{\text {len }}$, width $b_{\text {width }}$, and thickness $h_{\text {thick }}$. The term $U^{\mathrm{FB}}$ is the strain energy in the fiber bundle with length $\rho_{q, \text { local }}^{\text {trans }}$, as given by:

$$
U^{\mathrm{FB}}\left(\rho_{q, \text { local }}^{\text {trans }}\right)=\frac{A_{U 2}^{\text {trans }}}{2 \rho_{q, \text { local }}^{\text {trans }}}\left(\varepsilon^{\mathrm{FB}}\right)^{\mathrm{T}}\left(\boldsymbol{S}^{\mathrm{FB}}\right)^{-1} \varepsilon^{\mathrm{FB}}
$$

with

$$
A^{\mathrm{TI}}=b_{\text {len }} h_{\text {thick }}, \quad A^{\mathrm{TO}}=b_{\text {width }} b_{\text {len }}
$$

The superscripts FB denote the properties of the fiber bundle and $\varepsilon^{\mathrm{FB}}$ is the fiber bundle strain. (4) When the energy criterion in Eq. (14) is satisfied, the virtual transverse crack density $\rho_{q, \text { local }}^{\text {trans }}$ increased by $\Delta \rho$ and step (2) was repeated while the stress and energy criteria were satisfied. When the stress criterion or the energy criterion were not satisfied under constant strains, the new transverse crack density $\rho_{q \text {, local }}^{\text {trans }}$ in the local area was determined. The transverse crack density $\rho_{q}^{\text {trans, } n}$ considering the effect of stress transfer 
arising from fiber/matrix debonding around the matrix cracks in other fiber bundles, was calculated by substituting $\rho_{q, \text { local }}^{\text {trans }}$ and Eq. (35) into Eq. (36). The stiffness reduction $V_{\text {del }}^{k}$ was calculated using the average matrix crack spacing $\bar{x}^{k}$ and the average interfacial debonding length $\delta^{k}$ in the $k$-direction fiber bundle with matrix cracks. The damage variable $d_{11}^{\mathrm{L}}$ associated with the matrix crack density in each element was evaluated using Eqs. (21), (22), and (23).

The nonlocal damage theory established by Bažant and PijaudierCabot (Bažant and Pijaudier-Cabot, 1988) was adopted for two reasons: to prevent nonphysical damage localization by a fine mesh and to average physical damage (e.g., matrix and transverse crack densities) on a bundle scale. The latter reason is necessary for comparing the mesomechanical model with the micromechanical model, which calculates the averaged crack densities on the fiber bundle. Based on nonlocal damage theory, the non-localization of damage variables $d_{i j}$ at a point $x$ in the fiber bundle was achieved as follows:

$$
\begin{aligned}
\bar{d}_{i j}(\boldsymbol{x}) & =\frac{1}{V_{r}(\boldsymbol{x})} \int_{V} h(\boldsymbol{s}-\boldsymbol{x}) d_{i j}(\boldsymbol{s}) d V(\boldsymbol{s}), \\
h(\boldsymbol{x}) & =\exp \left[-\frac{k_{D}|\boldsymbol{x}|^{2}}{\omega^{2}}\right] \\
V_{r}(\boldsymbol{x}) & =\int_{V} h(\boldsymbol{s}-\boldsymbol{x}) d V(\boldsymbol{s})
\end{aligned}
$$

where $\bar{d}_{i j}$ is the non-local damage variable, $h$ is the Gaussian distribution function, $V_{r}$ is the reference volume, $k_{D}$ is the dimension number, and $\omega$ is the characteristic length. In this study, $k_{D}=3$, and the characteristic length $\omega$ was set to the half thickness of the fiber bundle to average damage variables in the fiber bundle. The ultimate tensile strength of the 3D woven composite was determined when the failure condition in Eq. (34) was satisfied for an element.

\section{Experiments}

The tested specimen was an orthogonal 3D woven Tyranno ${ }^{\mathrm{TM}} \mathrm{ZMI}$ fiber $(56 \% \mathrm{Si}, 1$ $\% \mathrm{Zr}, 34 \% \mathrm{C}, 9 \%$ O: Ube Industries, Ltd.)/Si-Ti-C-O matrix composite with unit cell B (Higuchi et al., 2016; Suzuki et al., 2015). The volume fractions of the fiber bundles in the $X$ and $Z$ directions were largest and smallest, respectively, compared to the fiber bundles in other directions. The matrix was generated by chemical vapor infiltration (CVI), solid phase infiltration (SPI), and polymer impregnation and pyrolysis (PIP). The fiber bundle contained fibers and a CVI matrix around the fibers, and the pure matrix region was produced by SPI and PIP.

The microdamage and macro stress-strain response of the 3D woven $\mathrm{CMC}$ was evaluated using monotonic tensile testing and loading/unloading testing. Monotonic tensile testing was performed to determine the stress-strain responses in the $X, Y$, and $45^{\circ}$ directions. Dumbbell specimens were loaded in the $X, Y$, and $45^{\circ}$ directions. Loading/unloading testing was performed to investigate transverse and matrix cracking 
in dumbbell specimens subjected to tensile loading in the $X$ or $Y$ direction. The free edge of each dumbbell specimen was polished using a diamond grinding disk (Buehler Ltd.) to observe the transverse and matrix cracks based on the replica method (ASTM E1351-01(2012), 2012) using RepliSet (Struers). Loading/unloading testing was conducted using the following three steps. (1) A tensile load was applied to the specimen. (2) The specimen was maintained at a specific load, and the matrix and transverse cracks on the free edge were observed based on the replica method. (3) The specimen was unloaded until the load reached zero. This loading/unloading cycle was repeated until the specimen failed. The matrix and transverse crack densities under failure stress were measured at the free edge of the failed specimen.

\section{Comparing the prediction with the experiment}

\section{Orthogonal 3D woven Si-Ti-C-O/Si-Ti-C-O composite}

The matrix and transverse crack evolutions and nonlinear stress-strain behavior of unit cell A of the 3D woven Si-Ti-C-O/Si-Ti-C-O composite under $X$-direction tensile loading were analyzed to compare with the experimental results of Ogasawara et al. (Ogasawara et al., 2004). The mechanical properties of the fiber, matrix, and pure matrix are shown in Table 1. The pure matrix region in unit cell A has many voids; (Ogasawara et al., 2004) therefore, the Young's modulus of the pure matrix $E_{m}^{\text {pure }}$ was determined by fitting the Young's modulus of unit cell A, calculated using the micromechanical model, to the experiment result (141 GPa (Ogasawara et al., 2004)). Table 2 lists the material properties of the matrix crack evolution and fiber breakage in the $X$-direction fiber bundle. Table 3 shows the material properties of the transverse crack evolution in the $Y$ and $Z$ fiber bundles. Because the shear stresses in each bundle are zero for the 3D woven composite subjected to $X$ - or $Y$-direction tensile loading, $\alpha_{k}^{\mathrm{TI}}=$ $\alpha_{k}^{\mathrm{TO}}=\alpha_{k}^{\mathrm{L}}=\beta_{k}^{\mathrm{TI}}=\beta_{k}^{\mathrm{TO}}=\beta_{k}^{\mathrm{L}}=0$ was assumed in this analysis. Parameters $\sigma_{11 i}^{\mathrm{X}}$, $\sigma_{\mathrm{deb}}^{\mathrm{X}}, \sigma_{\mathrm{R}}^{\mathrm{X}}, m_{1}^{\mathrm{X}}$, and $\bar{x}_{s}^{\mathrm{X}}$ were determined by fitting the matrix crack evolution predicted by the micromechanical model to that obtained experimentally results. The critical stress $\sigma_{22 c}^{\mathrm{Y}}$ was also determined by fitting the transverse crack evolution calculated by the

Table 1. Mechanical properties of the fiber, matrix, and pure matrix (Ogasawara et al., 2004)

\begin{tabular}{lc}
\hline Young's modulus of the fiber, $E_{f}(\mathrm{GPa})$ & 185 \\
Poisson's ratio of the fiber, $\nu_{f}(-)$ & 0.2 \\
Shear modulus of the fiber, $G_{f}(\mathrm{GPa})$ & 77.08 \\
Volume fraction of the fiber in unit cell $\mathrm{A}, V_{f}^{\text {unit }}(-)$ & 0.413 \\
Fiber volume fraction in the fiber bundle, $V_{f}(-)$ & 0.543 \\
Young's modulus of the matrix, $E_{m}(\mathrm{GPa})$ & 185 \\
Poisson's ratio of the matrix, $\nu_{m}(-)$ & 0.2 \\
Shear modulus of the matrix, $G_{m}(\mathrm{GPa})$ & 77.08 \\
Young's modulus of pure matrix, $E_{m}^{\mathrm{pure}}(\mathrm{GPa})$ & 29.7 \\
Poisson's ratio of pure matrix, $\nu_{m}^{\text {pure }}(-)$ & 0.2 \\
Shear modulus of pure matrix, $G_{m}^{\text {pure }}(\mathrm{GPa})$ & 12.375 \\
\hline
\end{tabular}


Table 2. Material properties for matrix crack evolution and fiber breakage.

\begin{tabular}{lc}
\hline Minimum cracking stress, $\sigma_{11 i}^{\mathrm{X}}(\mathrm{MPa})$ & 190 \\
Debonding stress, $\sigma_{\mathrm{deb}}^{\mathrm{X}}(\mathrm{MPa})$ & 380 \\
Critical matrix cracking stress, $\sigma_{\mathrm{R}}^{\mathrm{X}}(\mathrm{MPa})$ & 950 \\
Weibull modulus for the flaw strength distribution, $m_{1}^{\mathrm{X}}(-)$ & 3.5 \\
Statistical parameter, $\Lambda^{\mathrm{X}}(-)$ & 1.927264 \\
Characteristic crack spacing, $\bar{x}_{s}^{\mathrm{X}}(\mu \mathrm{m})$ & 44.5 \\
Longitudinal length for the matrix cracking observation, $L(\mathrm{~mm})$ & 0.6 (Ogasawara et al., 2004) \\
Fiber radius, $r(\mu \mathrm{m})$ & 4.25 (Ogasawara et al., 2004) \\
Weibull modulus for the fiber strength, $m_{2}(-)$ & 4.19 (Davies et al., 1999) \\
Characteristic strength for the fibers, $\sigma_{c}(\mathrm{GPa})$ & 3.09 (Davies et al., 1999) \\
\hline
\end{tabular}

Table 3. Material parameters for transverse crack evolution.

\begin{tabular}{lc}
\hline Critical energy release rate, $\Gamma_{c}^{\mathrm{Y}}$ and $\Gamma_{c}^{\mathrm{Z}}(\mathrm{J} / \mathrm{m})$ & 8.0 (Ogasawara et al., 2004) \\
Critical stress, $\sigma_{22 c}^{\mathrm{Y}}$ and $\sigma_{33 c}^{\mathrm{Z}}(\mathrm{MPa})$ & 120 \\
\hline
\end{tabular}
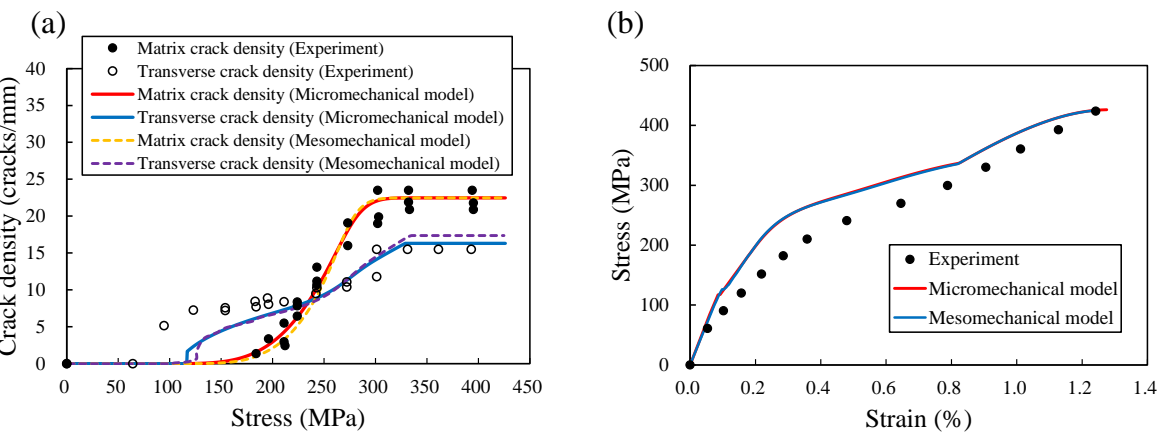

Figure 10. (a) Matrix and transverse crack evolutions and (b) stress-strain response of the orthogonal 3D woven $\mathrm{Si}-\mathrm{Ti}-\mathrm{C}-\mathrm{O} / \mathrm{Si}-\mathrm{Ti}-\mathrm{C}-\mathrm{O}$ composite calculated by the micromechanical and mesomechanical models, together with the experimental results (Ogasawara et al., 2004).

micromechanical model to that obtained experimentally. The critical energy release rate and critical stress of the $Z$-direction fiber bundle were assumed to be equal to those of the $Y$-direction fiber bundle.

The predicted results for the matrix crack density in the $X$ bundle and transverse crack density in the $Y$ bundle using the micromechanical and mesomechanical models are shown in Fig. 10 (a), with the crack densities reported by Ogasawara et al. (Ogasawara et al., 2004) also shown. The transverse and matrix crack densities calculated by the micromechanical model correlate well with those predicted by the mesomechanical model, which indicates that the stress disturbance in the fiber bundles arising from the geometry of the unit cell is small, and that three-dimensional laminate theory is effective for predicting the effective stiffness of the $3 \mathrm{D}$ woven CMC. The micromechanical and mesomechanical models were able to reproduce the saturated 
Table 4. Ultimate tensile strength of 3D woven Si-Ti-C-O/Si-Ti-C-O composites.

\begin{tabular}{ccc}
\hline Experiments (Ogasawara et al., 2004) & Micromechanical model & Mesomechanical model \\
\hline $423.8 \mathrm{MPa}$ & $426.0 \mathrm{MPa}$ & $424.7 \mathrm{MPa}$ \\
\hline
\end{tabular}

transverse crack density of the experimental results because the stresses in the $Y$ and $Z$ fiber bundles gradually decreased through the stress redistribution due to the growth of fiber/matrix interfacial debonding around the matrix cracks in the $X$ fiber bundle.

The initial transverse cracking stress predicted by the two models exceed that observed the experimentally. This discrepancy may be due to the assumption that the pure matrix region is undamaged. Experimentally, cracks initiate in the pure matrix region at very low stress levels. The cracks in the pure matrix region grew in the $Y$ - and $Z$-direction fiber bundles owing to stress concentration at the crack tip. Therefore, the initial transverse cracking stress observed experimentally is lower than that in the present models, which are considered undamaging states in the pure matrix region at any stress level. Another reason is the statistical variability of the fracture parameters in a bundle due to initial defects. In this study, a deterministic approach that assumes the average critical energy release rate and critical stress in a fiber bundle, was employed. These fracture parameters are statistically distributed in the fiber bundle due to initial defects during manufacturing. Hajikazemi et al. (Hajikazemi et al., 2020) analyzed transverse crack progression in carbon-fiber-reinforced plastic laminates using an energy-based approach, considering the statistical distribution of the critical energy release rate in cracked plies. They demonstrated that the region of weakness due to defects results in a low initial transverse cracking stain, as reported by Bertheolt and Corre (Berthelot and Le Corre, 2000). However, the predicted results reproduced the experimental results at a high stress level, and the deterministic approach for transverse crack progression was valid for predicting the failure strength and strain of the $3 \mathrm{D}$ woven CMC.

Figure 10 (b) depicts the stress-strain response predicted by the micromechanical and mesomechanical models with peak stress obtained by loading/unloading testing (Ogasawara et al., 2004). The two models are in good agreement with the experimental results up to the failure point. With the exception of ultimate failure strength, the micromechanical and mesomechanical models produced almost identical results. Table 4 shows the ultimate failure strengths predicted by the micromechanical model and the mesomechanical model, and that obtained experimentally. The strength predicted by the mesomechanical model was slightly lower than that of the micromechanical model because stress disturbance arising from the microstructural geometry is considered in the mesomechanical model. Therefore, the mesomechanical model enabled more appropriate results to be obtained than the micromechanical model. However, the discrepancy between the micomechanical and mesomechanical models is negligible, and the strengths predicted by the mesomechanical and micromechanical models correlate well with the experimental results. 

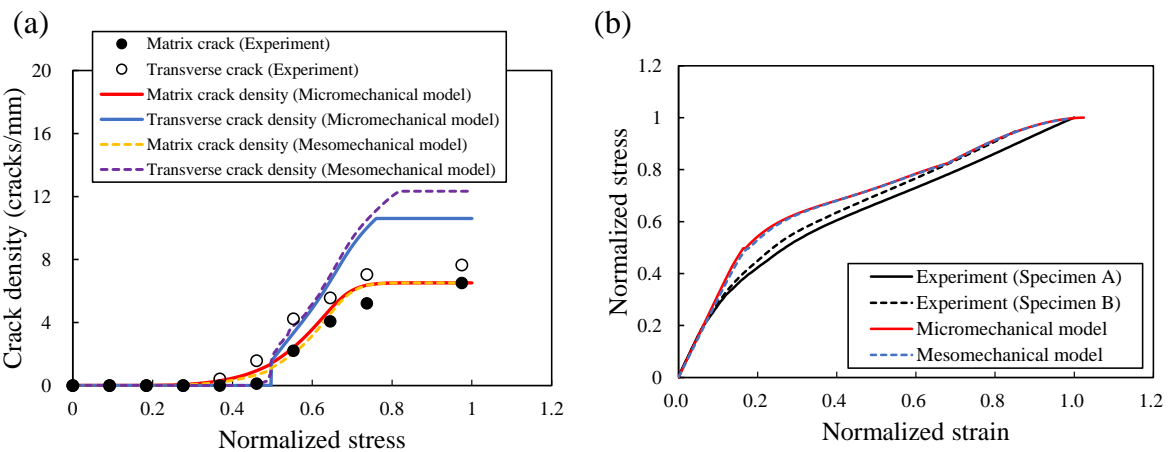

Figure 11. (a) Matrix and transverse crack evolutions and (b) stress-strain response of the orthogonal 3D woven Tyranno ${ }^{\mathrm{TM}} \mathrm{ZMI} / \mathrm{Si}$-Ti-C-O composite under $X$-direction tensile loading calculated by the micromechanical and mesomechanical models and compared with the experimental results. Stresses and strains were normalized against the ultimate tensile strength and failure strain of specimen $A$.

\section{Orthogonal 3D woven Tyranno ${ }^{T M} Z M I / S i-T i-C-O$ composite}

The experimental results for the orthogonal 3D woven Tyranno ${ }^{\mathrm{TM}} \mathrm{ZMI} / \mathrm{Si}-\mathrm{Ti}-\mathrm{C}-\mathrm{O}$ composite under in-plane loading were summarized and compared with the results predicted by the micromechanical and mesomechanical models. The values of the Weibull modulus, $m_{2}$, and characteristic strength, $\sigma_{c}$, for the fibers obtained by Davies et al. (Davies et al., 1999) were adopted (Table 2). The longitudinal length $L$ for the matrix cracking observation was $1.6 \mathrm{~mm}$, and the fiber radius $r$ was $5.5 \mu \mathrm{m}$. The material parameters for the matrix and transverse crack evolutions in each fiber bundle were determined by fitting the results predicted by the micromechanical model with the experimental results of the $X$ - and $Y$-direction tensile loadings.

Figure 11 shows the matrix and transverse crack densities and the stress-strain relationship of the $3 \mathrm{D}$ woven composite subjected to $X$-direction tensile loading predicted by the micromechanical and mesomechanical models with the experimental results of two specimens (specimens $\mathrm{A}$ and B). The material parameters for the matrix crack evolution in the $X$ bundle and transverse crack evolution in the $Y$ and $Z$ bundles are listed in Tables 5 and 6, respectively, in which the stresses and strains are normalized against the ultimate tensile strength and failure strain of specimen A. The saturated transverse crack densities predicted by the micromechanical and mesomechanical models are slightly higher than those obtained experimentally. However, the prediction of the two models correlate reasonably with the experimental data. The initial transverse cracking stresses predicted by the two models are lower than the experimental values owing to stress concentration near the crack tip in the pure matrix region and the statistical distribution of the fracture parameters in the fiber bundle, as discussed in the previous subsection. 
Table 5. Material properties for matrix crack evolution in the $X$-direction fiber bundle.

\begin{tabular}{lc}
\hline Minimum cracking stress, $\sigma_{11 i}^{\mathrm{X}}(-)$ & $0.192^{\mathrm{a}}$ \\
Debonding stress, $\sigma_{\mathrm{deb}}^{\mathrm{X}}(-)$ & $0.384^{\mathrm{a}}$ \\
Critical matrix cracking stress, $\sigma_{\mathrm{R}}^{\mathrm{X}}(-)$ & $1.92^{\mathrm{a}}$ \\
Weibull modulus for the flaw strength distribution, $m_{1}^{\mathrm{X}}(-)$ & 3.9 \\
Statistical parameter, $\Lambda^{\mathrm{X}}(-)$ & 1.86848 \\
Characteristic crack spacing, $\bar{x}_{s}^{\mathrm{X}}(\mu \mathrm{m})$ & 153.5 \\
\hline${ }^{\mathrm{a}}$ Stress is normalized against the ultimate tensile strength of specimen A
\end{tabular}

Table 6. Material parameters for transverse crack evolution in $Y$ - and $Z$-direction fiber bundles.

\begin{tabular}{lc}
\hline Critical energy release rate, $\Gamma_{c}^{\mathrm{Y}}$ and $\Gamma_{c}^{\mathrm{Z}}(\mathrm{J} / \mathrm{m})$ & 25.0 \\
Critical stress, $\sigma_{22 c}^{\mathrm{Y}}$ and $\sigma_{33 c}^{\mathrm{Z}}$ & $0.436^{\mathrm{a}}$ \\
\hline${ }^{\mathrm{a}}$ Stress is normalized against the ultimate tensile strength of specimen A
\end{tabular}

Table 7. Material properties for matrix crack evolution in the $Y$-direction fiber bundle.

\begin{tabular}{lc}
\hline Minimum cracking stress, $\sigma_{11 i}^{\mathrm{Y}}(-)$ & $0.265^{\mathrm{a}}$ \\
Debonding stress, $\sigma_{\mathrm{deb}}^{\mathrm{Y}}(-)$ & $1.06^{\mathrm{a}}$ \\
Critical matrix cracking stress, $\sigma_{\mathrm{R}}^{\mathrm{Y}}(-)$ & $2.65^{\mathrm{a}}$ \\
Weibull modulus for the flaw strength distribution, $m_{1}^{\mathrm{Y}}(-)$ & 4.5 \\
Statistical parameter, $\Lambda^{\mathrm{Y}}(-)$ & 1.88937 \\
Characteristic crack spacing, $\bar{x}_{s}^{\mathrm{Y}}(\mu \mathrm{m})$ & 180.1 \\
\hline a Stress is normalized against the ultimate tensile strength of specimen C
\end{tabular}

A photographic image of the replica observation in the $X-Z$ plane of the 3D woven CMC under $X$-direction tensile loading is shown in Fig. 12. Transverse cracks initially propagate in the $Y$-direction fiber bundles at low stress levels (Fig. 12 (b)). These transverse cracks penetrate the $X$ bundles, and matrix cracks initiate in the $X$ direction fiber bundles (Fig. 12 (c)). Kuo and Chou (Kuo and Chou, 1995) defined transverse cracks that penetrate the matrix crack as major cracks; they result in a relatively large stiffness reduction (Okabe et al., 1998). At high stress levels, major and minor cracks (Kuo and Chou, 1995) that only exist in $0^{\circ}$ plies were observed (Fig. 12 (d)). Therefore, to capture crack propagation, it is necessary to calculate both the major and minor cracks. The crack progression analysis used in the micromechanical and mesomechanical models can be used to model major and minor cracks. As shown in Fig. 11 (b), the stress-strain response calculated by the micromechanical and mesomechanical models correlate well with the experimental results, up to ultimate failure.

The transverse and matrix crack evolutions and stress-strain curve of the 3D woven composite subjected to $Y$-direction tensile loading predicted by the micromechanical and mesomechanical models are shown in Fig. 13 along with the experimental results of two specimens (specimens $\mathrm{C}$ and D). Table 7 lists the material parameters for matrix crack progression in the $Y$-direction fiber bundle, and Table 8 shows the material parameters for transverse crack evolution in the $X$ - and $Z$-direction fiber bundles. The stresses 
(a)

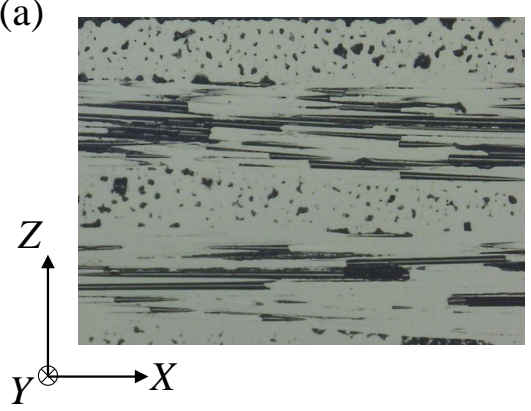

(c)

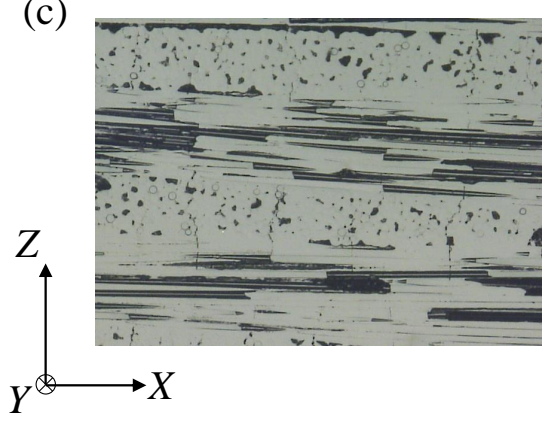

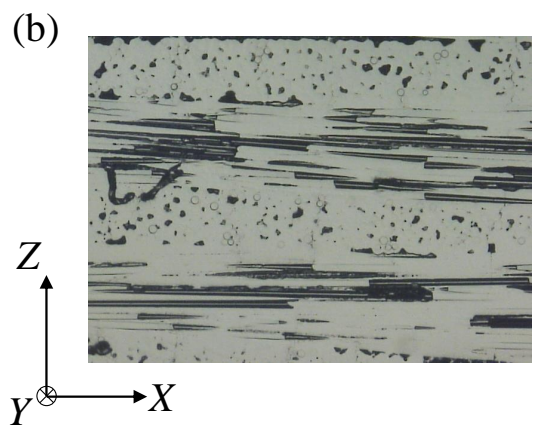

(d)

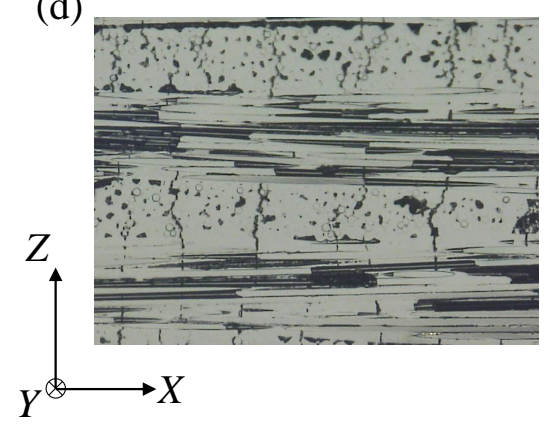

Figure 12. Photographic images of the replica observation in 3D woven Tyranno ${ }^{\mathrm{TM}} \mathrm{ZMI}$ fiber/Si-Ti-C-O matrix composite under tensile loading along the $X$ axis at normalized stress values of (a) 0 , (b) 0.4361 , (c) 0.5233 , and (d) 0.6978 . Stresses are normalized against the ultimate tensile strength of specimen $A$.

Table 8. Material parameters for transverse crack evolution in the $X$-and $Z$-direction fiber bundles.

Critical energy release rate, $\Gamma_{c}^{\mathrm{X}}$ and $\Gamma_{c}^{\mathrm{Z}}(\mathrm{J} / \mathrm{m}) \quad 13.0$

Critical stress, $\sigma_{22 c}^{\mathrm{X}}$ and $\sigma_{22 c}^{\mathrm{Z}}(\mathrm{MPa}) \quad 0.318^{\mathrm{a}}$

${ }^{a}$ Stress is normalized against the ultimate tensile strength of specimen $\mathrm{C}$

and strains were normalized against the ultimate strength and failure strain of specimen C, respectively. As was observed in Fig. 10, the two models are able to reproduce the experimental results. However, there is a large difference between the experimental results of specimens $\mathrm{C}$ and $\mathrm{D}$, which is ascribable to material variability arising from the impregnation rate of the matrix in the fiber bundle during the CVI process. From the results shown in Figs. 10, 11, and 13, the micromechanical models presented in this study are able to reasonably reproduce the results from the mesomechanical model and those obtained experimentally. 
(a)

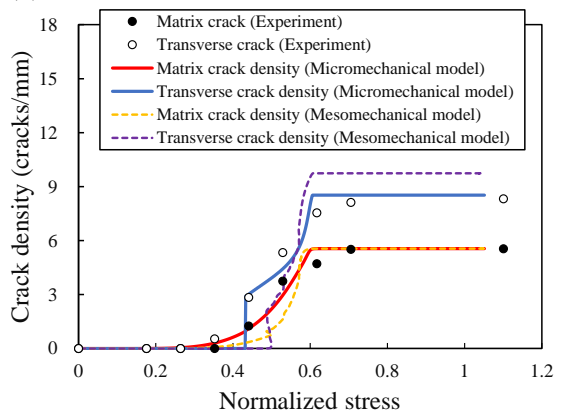

(b)

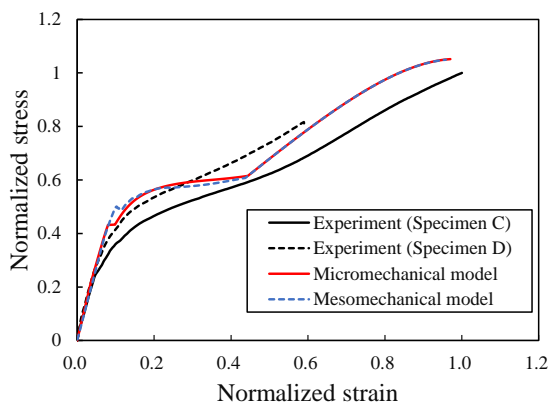

Figure 13. (a) Matrix and transverse crack evolutions, and (b) stress-strain responses of orthogonal 3D woven Tyranno ${ }^{\mathrm{TM}} \mathrm{ZMI} / \mathrm{Si}-\mathrm{Ti}-\mathrm{C}-\mathrm{O}$ composite under $Y$-direction tensile loading as calculated by the micromechanical and mesomechanical models with experimental results also shown. Stresses and strains are normalized against the ultimate tensile strength and failure strain of specimen $\mathrm{C}$.

The mechanical response of the $3 \mathrm{D}$ woven $\mathrm{CMC}$ subjected to $45^{\circ}$ tensile loading was analyzed using a micromechanical model. The parameters for the matrix and transverse crack progression that were used in each fiber bundle are shown in Tables 5-8. Furthermore, the influence of mixed-mode ratios on the stress-strain behavior under in-plane loading was evaluated by considering the mixed-mode ratios as $\alpha_{k}^{\mathrm{L}}=$ $\alpha_{k}^{\mathrm{TI}}=\alpha_{k}^{\mathrm{TO}}=0,1,2,3$ and $\beta_{k}^{\mathrm{L}}=\beta_{k}^{\mathrm{TI}}=\beta_{k}^{\mathrm{TO}}=0$. Because out-of-plane shear stresses in each fiber bundle are zero under in-plane ( $X$-, $Y$-, or $45^{\circ}$-direction) tensile loading, $\beta_{k}^{\mathrm{L}}=\beta_{k}^{\mathrm{TI}}=\beta_{k}^{\mathrm{TO}}=0$ was considered.

Figure 14 shows the stress-strain diagram under $45^{\circ}$ tensile loading as predicted by the micromechanical model, together with experimental results. Stress and strain were normalized against the experimental ultimate tensile strength and failure strain. When the mixed-mode ratios were equal to 3 , the predicted result was in good agreement with the experimental result, which indicates that shear stresses significantly contribute to the stiffness reduction in 3D woven composites when shear loading is applied. When the material parameters were determined using $X, Y$, and $45^{\circ}$ tensile tests conducted in this study, the micromechanical model was able to reproduce the stress-strain relationship of the 3D woven CMC under in-plane multiaxial loads.

Recently, Higuchi et al. (Higuchi et al., 2016) established a macromechanical model for damaged 3D woven composites based on phenomenological stiffness degradation. Using micromechanical and macromechanical models, the multiscale modeling of bridging damage at the micro level to the multiaxial stress distribution at the macro level can be established. The macromechanical model is easily applied to FEA without predicting transverse and matrix crack densities; therefore, the stress distribution in a structure can be analyzed. When the stresses in a structure comprising 3D woven CMC were obtained using a macromechanical model, the micromechanical model was able to 


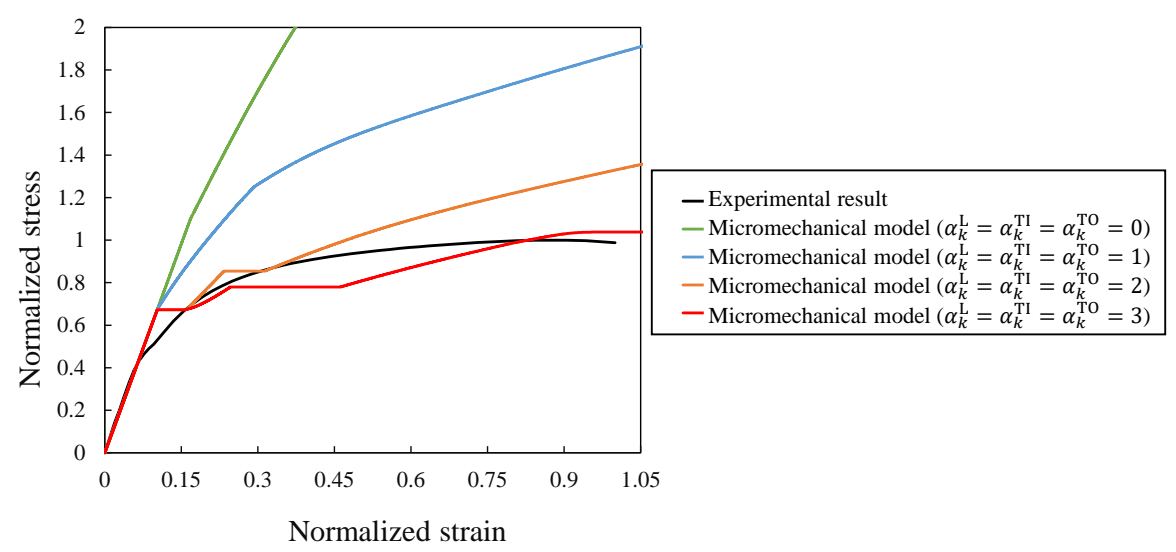

Figure 14. Stress-strain responses of the orthogonal $3 \mathrm{D}$ woven Tyranno ${ }^{\mathrm{TM}} \mathrm{ZMI} / \mathrm{Si}-\mathrm{Ti}-\mathrm{C}-\mathrm{O}$ composite under $45^{\circ}$ direction tensile loading calculated by micromechanical model, along with experimental results. Stresses and strains are normalized against the experimental ultimate tensile strength and failure strain.

reproduce the transverse and matrix crack densities in the 3D woven CMC subjected to multiaxial loading predicted by the macromechanical model.

\section{Conclusion}

This study formulated a micromechanical model for 3D woven composites with transverse and matrix cracks subjected to in-plane loading. The three-dimensional effective compliance of the 3D woven composite was derived using three-dimensional laminate theory. The damage variables were formulated using the models developed by Onodera and Okabe (Onodera and Okabe, 2020) and Curtin et al. (Curtin et al., 1998) to describe the stiffness reduction in the fiber bundle with transverse and matrix cracking. The method for transverse and matrix crack progression under in-plane loading was established by introducing mixed-mode damage criteria. This study considered the stress redistribution among fiber bundles in the 3D woven composites due to fiber/matrix interfacial debonding around matrix cracking. In addition, a mesomechanical model was established (using FEA) to evaluate the stress disturbance in fiber bundles arising from the geometry of the unit cell.

The transverse and matrix crack evolutions and stress-strain responses of 3D woven composites were predicted under $X, Y$, and $45^{\circ}$ direction tensile loading using micromechanical and mesomechanical models and were compared with the results of those obtained experimentally. The micromechanical and mesomechanical models reproduced the saturated transverse crack densities by considering the stress redistribution arising from the fiber/matrix interfacial debonding. The stress-strain curves for a 3D CMC under $X$ - and $Y$-direction tensile loading predicted by both models 
are in good agreement with the experimental results up to the ultimate strength and failure strain. Thus, the results of the micromechanical model, which does not consider stress disturbance in the fiber bundles of 3D woven composites, reasonably agree with those of the mesomechanical model. Therefore, the stress disturbance arising from the geometry in the fabric structure is extremely small. Moreover, the mechanical response of the 3D woven $\mathrm{CMC}$ subjected to $45^{\circ}$ tensile loading was analyzed using a micromechanical model. The stress-strain response under tensile and shear loading was predicted by introducing mixed-mode damage criteria that contributes to the transverse and matrix crack progressions.

\section{Acknowledgements}

The authors would like to thank Mr. Tatsuhito Honda, Mr. Yusuke Ueda, Mr. Daichi Haruyama, and Mr. Hayao Sato of IHI Corporation for providing us with technical assistance for the experiments. The authors would also like to acknowledge the vitally important encouragement and support made through the University of Washington-Tohoku University: Academic Open Space (UW-TU: AOS).

\section{Funding}

T. O. is grateful for the support of the Council for Science, Technology and Innovation (CSTI), Cross-ministerial Strategic Innovation Promotion Program (SIP), and "Materials Integration" for Revolutionary Design System of Structural Materials (Funding agency: JST). S. O. appreciates the support of JSPS KAKENHI [grant number JP 18J20899]. This study is conducted under the sponsored research by NEDO (New Energy and Industrial Technology Development Organization).

\section{Declaration of conflicting interests}

The authors declare that there is no conflict of interest.

\section{References}

ABAQUS. “6.13 Documentation.” Dassault Systemes Simulia Corporation .

Allen, D.H., Harris, C.E., and Groves, S.E. "A thermomechanical constitutive theory for elastic composites with distributed damage-I. Theoretical development." International Journal of Solids and Structures 23.9 (1987a): 1301-1318.

. "A thermomechanical constitutive theory for elastic composites with distributed damage-II. Application to matrix cracking in laminated composites." International Journal of Solids and Structures 23.9 (1987b): 1319-1338.

ASTM E1351-01(2012). Standard Practice for Production and Evaluation of Field Metallographic Replicas. West Conshohocken, PA: ASTM International, 2012.

Aveston, J., Cooper, G. A., and Kelly, A. "The Properties of Fibre Composites." Conference Proceedings, National Physical Laboratory. Guildford: IPC Science and Technology Press Ltd,, 1971, 15-26. 
Baucom, J.N. and Zikry, M.A. "Low-velocity impact damage progression in woven Eglass composite systems." Composites Part A: Applied Science and Manufacturing 36.5 (2005): 658-664.

Bažant, Zdeněk P. and Pijaudier-Cabot, Gilles. "Nonlocal continuum damage, localization instability and convergence." Journal of Applied Mechanics, Transactions ASME 55.2 (1988): 287-293.

Berthelot, J.-M. and Le Corre, J.-F. "Statistical analysis of the progression of transverse cracking and delamination in cross-ply laminates." Composites Science and Technology 60.14 (2000): 2659-2669.

Berthelot, Jean-Marie. "Transverse cracking and delamination in cross-ply glass-fiber and carbon-fiber reinforced plastic laminates: Static and fatigue loading." Applied Mechanics Reviews 56.1 (2003): 111.

Budiansky, Bernard, Hutchinson, John W., and Evans, Anthony G. "Matrix fracture in fiber-reinforced ceramics." Journal of the Mechanics and Physics of Solids 34.2 (1986): 167-189.

Chow, C.L. and Lu, T.J. "On evolution laws of anisotropic damage." Engineering Fracture Mechanics 34.3 (1989): 679-701.

Cox, Brian N., Dadkhah, Mahyar S., and Morris, W. L. "On the tensile failure of 3D woven composites." Composites Part A: Applied Science and Manufacturing 27.6 (1996): 447-458.

Curtin, W.A. "Multiple matrix cracking in brittle matrix composites." Acta Metallurgica et Materialia 41.5 (1993): 1369-1377.

- "Stress-Strain Behavior of Brittle Matrix Composites." Comprehensive Composite Materials Volume 4: Carbon/Carbon, Cement, and Ceramic Matrix Composites. eds. Anthony Kelly and Carl Zweben. Elsevier, 2000. 47-76.

Curtin, W.A., Ahn, B.K., and Takeda, N. "Modeling brittle and tough stress-strain behavior in unidirectional ceramic matrix composites." Acta Materialia 46.10 (1998): 3409-3420.

Davies, Ian J, Ishikawa, Takashi, Shibuya, Masaki, Hirokawa, Tetsuro, and Gotoh, J. "Fibre and interfacial properties measured in situ for a 3D woven SiC/SiC-based composite with glass sealant." Composites Part A: Applied Science and Manufacturing 30.4 (1999): 587-591.

Gudmundson, P. and Zang, W. "An analytic model for thermoelastic properties of composite laminates containing transverse matrix cracks." International Journal of Solids and Structures 30.23 (1993): 3211-3231. 
Hajikazemi, M., McCartney, L. N., and Van Paepegem, W. "Matrix cracking initiation, propagation and laminate failure in multiple plies of general symmetric composite laminates." Composites Part A: Applied Science and Manufacturing 136.February (2020): 105963.

Hansen, Lucas R and Waas, Anthony M. "A Three-Phase Shear-Lag Model for Longitudinal Cracking of a Ceramic Matrix Composite Ply With Thick Fiber Coatings.” Journal of Applied Mechanics 83.1 (2016): 011009.

Hashin, Z. "Analysis of stiffness reduction of cracked cross-ply laminates." Engineering Fracture Mechanics 25.5-6 (1986): 771-778.

Higuchi, R., Okabe, T., Ohtake, Y., Honda, T., Ueda, Y., and Ogihara, S. "Numerical simulation of damage progression and fracture in structures made of 3D woven ceramic matrix composites." Advanced Composite Materials 25.3 (2016): 209-227.

Hutchinson, John W. and Jensen, Henrik M. "Models of fiber debonding and pullout in brittle composites with friction." Mechanics of Materials 9.2 (1990): 139-163.

Ishikawa, Takashi, Bansaku, Kazuhiro, Watanabe, Naoyuki, Nomura, Yukimasa, Shibuya, Masaki, and Hirokawa, Tetsuro. "Experimental stress/strain behavior of SiCmatrix composites reinforced with Si-Ti-C-O fibers and estimation of matrix elastic modulus." Composites Science and Technology 58.1 (1998): 51-63.

Karandikar, Prashant and Chou, Tsu-Wei. "Characterization and modeling of microcracking and elastic moduli changes in nicalon/cas composites." Composites Science and Technology 46.3 (1993): 253-263.

Kravchenko, Oleksandr G., Kravchenko, Sergii G., and Pipes, R. Byron. "Chemical and thermal shrinkage in thermosetting prepreg." Composites Part A: Applied Science and Manufacturing 80: 72-81.

Kuo, Wen-Shyong and Chou, Tsu-Wei. "Multiple Cracking of Unidirectional and CrossPlyCeramic Matrix Composites." Journal of the American Ceramic Society 78.3 (1995): 745-755.

Lee, J.-W. and Daniel, I.M. "Progressive Transverse Cracking of Crossply Composite Laminates." Journal of Composite Materials 24.11 (1990): 1225-1243.

Longbiao, Li. "Modeling for Matrix Multicracking Evolution of Cross-ply CeramicMatrix Composites Using Energy Balance Approach.” Applied Composite Materials 22.6 (2015): 733-755.

Lopes, C.S., Camanho, P.P., Gürdal, Z., Maimí, P., and González, E.V. "Lowvelocity impact damage on dispersed stacking sequence laminates. Part II: Numerical simulations." Composites Science and Technology 69.7-8 (2009): 937-947. 
Murakami, Sumio. Continuum Damage Mechanics, vol. 185 of Solid Mechanics and Its Applications. Dordrecht: Springer Netherlands, 2012.

Ogasawara, Toshio, Ishikawa, Takashi, Ito, Hiroshi, Watanabe, Naoyuki, and Davies, Ian J. "Multiple Cracking and Tensile Behavior for an Orthogonal 3-D Woven Si-TiC-O Fiber/Si-Ti-C-O Matrix Composite." Journal of the American Ceramic Society 84.7 (2004): 1565-1574.

Ogi, Keiji, Okabe, Tomonaga, Takahashi, Manabu, Yashiro, Shigeki, Yoshimura, Akinori, and Ogasawara, Toshio. "Experimental characterization of high-speed impact damage behavior in a three-dimensionally woven $\mathrm{SiC} / \mathrm{SiC}$ composite." Composites Part A: Applied Science and Manufacturing 41.4 (2010): 489-498.

Ohnabe, Hisaichi, Masaki, Shoju, Onozuka, Masakazu, Miyahara, Kaoru, and Sasa, Tadashi. "Potential application of ceramic matrix composites to aero-engine components." Composites Part A: Applied Science and Manufacturing 30.4 (1999): 489-496.

Okabe, T, Takeda, N, Komotori, J, Shimizu, M, and Curtin, W.A. "A new fracture mechanics model for multiple matrix cracks of SiC fiber reinforced brittle-matrix composites." Acta Materialia 47.17 (1999): 4299-4309.

Okabe, T., Takeda, N., Komotori, J., Shimizu, M., Imai, Kazuwo, and Imai, Yoshio. "Tensile Matrix Cracking Behavior of Hi-Nicalon Fiber/Glass Matrix Cross-Ply Laminate Composites.” Key Engineering Materials 164-165: 221-224.

Okabe, Tomonaga, Onodera, Sota, Kumagai, Yuta, and Nagumo, Yoshiko. "Continuum damage mechanics modeling of composite laminates including transverse cracks." International Journal of Damage Mechanics 27.6 (2018): 877-895.

Onodera, Sota and Okabe, Tomonaga. "Three-dimensional analytical model for effective elastic constants of transversely isotropic plates with multiple cracks: Application to stiffness reduction and steady-state cracking of composite laminates." Engineering Fracture Mechanics 219.1 (2019): 106595.

- "Analytical model for determining effective stiffness and mechanical behavior of polymer matrix composite laminates using continuum damage mechanics." International Journal of Damage Mechanics 29.10 (2020): 1512-1542.

Rajan, Varun P. and Zok, Frank W. "Matrix cracking of fiber-reinforced ceramic composites in shear." Journal of the Mechanics and Physics of Solids 73: 3-21.

Sutcu, M. and Hillig, W.B. "The effect of fiber-matrix debond energy on the matrix cracking strength and the debond shear strength." Acta Metallurgica et Materialia 38.12 (1990): 2653-2662.

Suzuki, Takuya, Ohtake, Yasuhiro, Otani, Yoshihiro, Yonekura, Kazuo, and Ueda, Yusuke. "Prediction of stress-strain behavior of ceramic matrix composites using unit cell model.” MATEC Web of Conferences 29: 00011. 
Takeda, Nobuo and Kiriyama, Manami. "Matrix crack evolution in SiC fiber/glass matrix cross-ply laminates." Composites Part A: Applied Science and Manufacturing 30.4 (1999): 593-597.

Talreja, R. "A Continuum Mechanics Characterization of Damage in Composite Materials." Proceedings of the Royal Society A: Mathematical, Physical and Engineering Sciences 399.1817 (1985): 195-216.

Thouless, Michael D., Sbaizero, Orfeo, Sigl, Lorenz S., and Evans, Anthony G. "Effect of Interface Mechanical Properties on Pullout in a SiC-Fiber-Reinforced Lithium Aluminum Silicate Glass-Ceramic." Journal of the American Ceramic Society 72.4 (1989): 525-532.

Vinogradov, V. and Hashin, Z. "Variational analysis of cracked angle-ply laminates." Composites Science and Technology 70.4 (2010): 638-646.

Voyiadjis, George and Kattan, Peter. Advances in Damage Mechanics: Metals and Metal Matrix Composites With an Introduction to Fabric Tensors 2nd Edition. Elsevier, London, UK, 2006.

Walock, Michael J, Heng, Vann, Nieto, Andy, Ghoshal, Anindya, Murugan, Muthuvel, and Driemeyer, Dan. "Ceramic Matrix Composite Materials for Engine Exhaust Systems on Next-Generation Vertical Lift Vehicles." Journal of Engineering for Gas Turbines and Power 140.10 (2018): 102101.

Xia, Z.C., Carr, R.R., and Hutchinson, J.W. "Transverse cracking in fiber-reinforced brittle matrix, cross-ply laminates." Acta Metallurgica Et Materialia 41.8 (1993): 2365-2376.

Zok, Frank W. "Ceramic-matrix composites enable revolutionary gains in turbine engine efficiency." American Ceramic Society Bulletin 95.5 (2016): 22-28.

Zok, F.W. and Spearing, S.M. "Matrix crack spacing in brittle matrix composites." Acta Metallurgica et Materialia 40.8 (1992): 2033-2043. 